\title{
Invited review: Advances and applications of random regression models: From quantitative genetics to genomics
}

\author{
H. R. Oliveira, ${ }^{1,2}$ L. F. Brito, ${ }^{1,3}$ D. A. L. Lourenco, ${ }^{4}$ F. F. Silva, ${ }^{2}$ J. Jamrozik, ${ }^{1,5}$ L. R. Schaeffer, ${ }^{1}$ \\ and F. S. Schenkel ${ }^{1 *}$ \\ ${ }^{1}$ Centre for Genetic Improvement of Livestock, Department of Animal Biosciences, University of Guelph, Guelph, ON, N1G2W1, Canada \\ ${ }^{2}$ Department of Animal Science, Universidade Federal de Viçosa, Viçosa, Minas Gerais, 36570-000, Brazil \\ ${ }^{3}$ Department of Animal Sciences, Purdue University, West Lafayette, IN 47907 \\ ${ }^{4}$ Department of Animal and Dairy Science, University of Georgia, Athens 30602 \\ ${ }^{5}$ Canadian Dairy Network, Guelph, ON, N1K 1E5, Canada
}

\section{ABSTRACT}

An important goal in animal breeding is to improve longitudinal traits; that is, traits recorded multiple times during an individual's lifetime or physiological cycle. Longitudinal traits were first genetically evaluated based on accumulated phenotypic expression, phenotypic expression at specific time points, or repeatability models. Until now, the genetic evaluation of longitudinal traits has mainly focused on using random regression models (RRM). Random regression models enable fitting random genetic and environmental effects over time, which results in higher accuracy of estimated breeding values compared with other statistical approaches. In addition, RRM provide insights about temporal variation of biological processes and the physiological implications underlying the studied traits. Despite the fact that genomic information has substantially contributed to increase the rates of genetic progress for a variety of economically important traits in several livestock species, less attention has been given to longitudinal traits in recent years. However, including genomic information to evaluate longitudinal traits using RRM is a feasible alternative to yield more accurate selection and culling decisions, because selection of young animals may be based on the complete pattern of the production curve with higher accuracy compared with the use of traditional parent average (i.e., without genomic information). Moreover, RRM can be used to estimate SNP effects over time in genome-wide association studies. Thus, by analyzing marker associations over time, regions with higher effects at specific points in time are more likely to be identified. Despite the advances in applications of RRM in genetic evaluations,

Received January 8, 2019.

Accepted May 2, 2019.

*Corresponding author: schenkel@uoguelph.ca more research is needed to successfully combine RRM and genomic information. Future research should provide a better understanding of the temporal variation of biological processes and their physiological implications underlying the longitudinal traits.

Key words: genomic estimated breeding values, lactation curve, longitudinal trait, test-day

\section{INTRODUCTION}

An important goal in animal breeding is to improve longitudinal traits; that is, traits recorded multiple times during an individual's lifetime or physiological cycle, such as test-day milk yield (TDMY; Lennon and Mixner, 1958), egg production in birds, and periodic BW of growing animals. These traits were genetically evaluated based on accumulated production (e.g., milk production in $305 \mathrm{~d}$ ), at a specific time point (e.g., yearling weight), or using repeatability models. However, until now, the genetic evaluation of longitudinal traits has mainly focused on random regression models (RRM). In brief, RRM enable fitting random genetic and environmental effects over time (Schaeffer, 2004), which results in higher accuracy of EBV compared with other statistical models. In addition, RRM provide insights about temporal variation of biological processes and physiological implications underlying the studied traits (Strucken et al., 2015). Therefore, RRM generate relevant information to be exploited in breeding programs. For instance, selecting for an optimal shape of lactation curve in dairy species can reduce metabolic issues during the first weeks of lactation and the lactation peak, for example. In addition, RRM facilitate selection for increased lactation persistency.

Despite their advantages, RRM are not currently widely used for official genetic evaluations of longitudinal traits in species other than dairy. This is likely related to the fact that, ultimately, predictions of RRM are usually encapsulated into 1 or 2 values, which may 
not be greatly improved when taking into account the greater complexity of RRM compared with simpler models. Especially regarding the inclusion of genomic information, modeling time-dependent effects appears to be less important now with genomic models than previously with pedigree models. This is mainly related to the fact that the gain in EBV accuracy due to use of test-day records appears to be much lower than the gain in accuracy due to the inclusion of genomic information (Oliveira et al., 2019b). In addition, advantages of using test-day records can be reduced considering that selection decisions made on components of RRM may be less accurate compared with the use of accumulated production, for example, due to the use of less data in each specific time point. In the dairy cattle context, the inclusion of genomic information into RRM has also been limited by Interbull, because only one EBV per trait (and one genomic EBV; GEBV) is exchanged to perform multiple across-country evaluations (MACE; Interbull, 2017b). Thus, although genomic information has substantially contributed to increase the rates of genetic progress for various single-record traits in several livestock species (e.g., Goddard et al., 2010; Hayes and Goddard, 2010; Meuwissen et al., 2016), less attention has been given to RRM and longitudinal traits in the genomics era.

Regardless of the limitations mentioned above, genomic RRM can provide an opportunity to unravel genomic regions significantly associated with traits of interest at specific time points, as well as the trajectory of biological processes during the animal's life or production cycle. Thus, by analyzing marker associations over time, regions with higher effects in specific stages are more likely to be identified, which could contribute to better detection of the genetic variation of longitudinal traits (Strucken et al., 2015). Furthermore, using RRM in genomic predictions enables the selection of young animals based on the complete pattern of the production curve with higher accuracy compared with the use of traditional parent average (i.e., without genomic information; Oliveira et al., 2019b). Therefore, the main objectives of this review were (1) to present a comprehensive summary of the scientific contributions in the area of RRM applied to livestock breeding programs, with focus on dairy cattle; (2) to review the applications of RRM incorporating genomic information in a large number of livestock species; and (3) to discuss the challenges and suggest how genomic information can be successfully incorporated into RRM.

\section{DEVELOPMENT HISTORY}

In the genetic evaluation of dairy species, TDMY records were first used for genetic evaluation of accu- mulated 305-d milk yields (Voelker, 1981; Pander and Hill, 1993). In some countries such as Canada, the accumulated 305-d milk yield was initially estimated by summing the TDMY recorded every day during the lactation period. However, recording the amount of milk per cow every day was very costly, so countries used weekly or monthly records in their evaluations. Therefore, the weekly or monthly TDMY were combined by linear interpolation to produce the accumulated 305-d milk yield (Schaeffer, 2016).

Over the years, several statistical methods have been proposed to accurately estimate the accumulated yield based on TDMY records (e.g., Lamb and McGilliard, 1967; Wiggans and Van Vleck, 1979; Weller, 1988). Among them, the most efficient methods allowed adjustments to first and last test day and projection of incomplete lactations up to $305 \mathrm{~d}$ without reducing the total genetic variance (e.g., VanRaden et al., 1991). Thus, the accumulated 305-d yield of each lactation was used as single trait, and each lactation was separately analyzed in a single-trait model (e.g., Ferris et al., 1985; Banos and Shook, 1990) or together in a multiple-trait analysis (e.g., Rothschild and Henderson, 1979; Tong et al., 1979; Strandberg and Danell, 1989). Even though these methods have comparatively low computational demand (i.e., only one observation per animal per lactation), they do not provide information about the shape of the lactation curve. In addition, as several TDMY were combined into one single record per lactation, effects specific to individual TDMY were not taken into account, and projection factors were needed to estimate the accumulated 305-d yield from incomplete lactations (Ptak and Schaeffer, 1993). In this context, Norman et al. (1985) created projection factors to give the cow credit for milk not produced (e.g., if the cow left the herd before the end of lactation). Norman's factors were applied to all cows equally; however, this idea of projecting missing values is still implicitly used today under the RRM approach but using individualized projection factors for each cow.

Several alternatives were suggested to overcome these problems, such as analyzing the lactation curve parameters (coefficients) previously estimated in a first step (e.g., Shanks et al., 1981; Ferris et al., 1985; Ali and Schaeffer, 1987) or dividing the complete lactation into stages (e.g., months or trimesters of lactation) and analyzing these periods as separate traits in a multipletrait analysis (e.g., Auran, 1973; Lindgren et al., 1980; Agyemang et al., 1985). Attempts to use individual TDMY records as phenotypes in genetic evaluations were also evaluated to avoid loss of information and the approximations needed to project to 305-d lactations. In this case, TDMY records were considered repeated measurements of the same trait and modeled using 
repeatability models (e.g., Pander and Hill, 1993; Ptak and Schaeffer, 1993; Swalve, 1995). Alternatively, each TDMY could be considered as a different trait in a more complete and over-parameterized multiple-trait model approach, as suggested by Misztal et al. (2000).

Using both repeatability and multiple-trait models to analyze individual TDMY records presented considerable disadvantages. First, evaluating TDMY records based on a repeatability model assumes that the genetic correlation between the records is equal to 1 , which is unrealistic (Ptak and Schaeffer, 1993; Jensen, 2001). Second, assuming each TDMY record as a different trait generates a complex model with relatively few observations being analyzed for each trait. To decrease the number of traits in these multiple-trait models, studies defining trait as the test number after calving instead of DIM were also performed (e.g., Danell, 1982; Meyer et al., 1989).

For genetic evaluation of other traits such as BW, efforts were made to simplify the models and data collection, recognizing that the cost (in terms of time, labor, and disruption to the animal's daily life) of taking more measurements can be significant. For instance, this was done assuming specific standard ages to weight recording, such as birth, weaning, and yearling (e.g., Kennedy and Henderson, 1975; Schaeffer and Wilton, 1981; Trus and Wilton, 1988). The other alternative was to analyze the growth curve parameters (coefficients) estimated in a preliminary phenotypic analysis (e.g., Brown et al., 1972; DeNise and Brinks, 1985; Meyer, 1995) instead of actual weights measured at different ages, assuming weights as different traits in a multiple-trait animal model (e.g., Costa et al., 2011), or as repeated measurements using a repeatability model, as pointed out by Meyer (1999).

In general, those alternatives used to model longitudinal traits did not take into account that the correlation between phenotypes recorded at closer times or ages was higher than the correlation between more distant periods, and that the genetic and environmental variances may change over time (Ptak and Schaeffer, 1993). Thus, because the covariance pattern among the repeated measurements of longitudinal traits is well structured, different statistical methods are required to better account for the trait structure compared with single-measurement traits. Today, analyses of longitudinal data are carried out mainly based on RRM (e.g., Mota et al., 2018a; Padilha et al., 2018; Saghi et al., 2018).

\section{RANDOM REGRESSION MODELS}

Random regression models are an extension of the repeatability models in which the random genetic ani- mal effect can vary for each time period (Lidauer et al., 2003), without greatly increasing model complexity, as occurs in the multiple-trait models. Random regression models were initially proposed by Henderson (1982) and Laird and Ware (1982) as an alternative to overcome the problem of over-parametrization in multiple-trait analyses. However, the potential for practical application was only presented a decade later by Schaeffer and Dekkers (1994), in which the authors used RRM to analyze TDMY records in dairy cattle. In addition, the first genetic parameters for TDMY from RRM were published by Jamrozik and Schaeffer (1997), and the first results of genetic evaluation for milk yield derived from RRM were presented by Jamrozik et al. (1997b).

According to Schaeffer (2004), an RRM should contain a set of fixed curves describing the phenotypic relationship among the various groups of individuals, and a set of random regressions, which should include those for the additive genetic and the permanent environmental effects. Consequently, the genetic and permanent environmental correlation between phenotypes at different times can be different from 1 . In a general form, an RRM can be described as follows:

$$
y_{g i j}=\sum_{q=1}^{Q} b_{q g} z_{q g}+\sum_{r=1}^{R} a_{r i} z_{r i}+\sum_{s=1}^{S} p_{s i} z_{s i}+e_{g i j},
$$

where $y_{q i j}$ is the $j$ th repeated record of animal $i$ (e.g., TDMY records, BW at different ages); $b_{q g}$ is the $q$ th fixed regression coefficient for the gth group; $a_{r i}$ is the $r$ th random regression coefficient for additive genetic effect of the $i$ th animal; $p_{s i}$ is the $s$ th random regression coefficient for permanent environmental effect of the $i$ th animal; $e_{g i j}$ is the residual effect (which can have different variances depending on time); and $z_{q g}, z_{r i}$, and $z_{s i}$ are the covariates related to the function used to describe time (e.g., DIM, age at measurement), assuming here the same function (e.g., Legendre polynomial) with possible different orders $Q, R$, and $S$ (e.g., linear, quadratic, cubic). The fixed regressions for the groups are important to account for time trends in the phenotypes. In dairy cattle, the group is usually defined as yearmonth of calving or age-season of calving to account for time trends. In addition to the random regressions for the additive genetic and the permanent environmental effects, a random regression should be assumed for the parity-herd-year-season of calving effect in dairy cattle evaluations. The parity-herd-year-season of calving effect should be used to account for cows that share the same environmental effects throughout their lactation (i.e., contemporaries) instead of the fixed herd-yearseason effect that was being wrongly used (Schaeffer, 2016). Therefore, as argued by Schaeffer (2018), herd- 
test-day effects are no longer (and never should have been) recommended for test-day models.

In theory, the covariates $z$ can be any covariate; however, the covariates used in genetic evaluation of livestock species have been based on relatively simple polynomial functions that are known to fit the data reasonably well over time (Jensen, 2001). Numerous linear and nonlinear functions have been proposed for modeling the trajectory of effects included in the model. Among the most used linear functions are orthogonal polynomial functions, such as Legendre polynomials (Kirkpatrick et al., 1990), and the smoothing polynomial functions, such as spline (Wegman and Wright, 1983; White et al., 1999) and B-spline (de Boor, 1980; Meyer, 2005) functions. Linear and nonlinear parametric functions have also been described to analyze milk-related traits, such as by Wood (1967), Ali and Schaeffer (1987), and Wilmink (1987); and to describe growth rate traits, such as by Gompertz (1825), Brody and Lardy (1946), and von Bertalanffy (1957). Nonetheless, due to the difficulties to implement nonlinear parametric functions as regressions in RRM in currently available software for genetic evaluation, these functions have being linearized before their use (e.g., Oliveira et al., 2016). A more in depth comparison and discussion on the functions currently used as regressions in RRM is presented later in the section titled Comparison of Alternative Functions to Model Trajectory Curves.

Henderson's mixed model equations (MME; Henderson, 1963, 1973, 1982) for RRM can be described as follows:

$$
\begin{aligned}
& {\left[\begin{array}{ccc}
\mathbf{X}^{\prime} \mathbf{R}^{-1} \mathbf{X} & \mathbf{X}^{\prime} \mathbf{R}^{-1} \mathbf{Z} & \mathbf{X}^{\prime} \mathbf{R}^{-1} \mathbf{W} \\
\mathbf{Z}^{\prime} \mathbf{R}^{-1} \mathbf{X} & \mathbf{Z}^{\prime} \mathbf{R}^{-1} \mathbf{Z}+\mathbf{A}^{-1} \otimes \mathbf{G}_{0}^{-1} & \mathbf{Z}^{\prime} \mathbf{R}^{-1} \mathbf{W} \\
\mathbf{W}^{\prime} \mathbf{R}^{-1} \mathbf{X} & \mathbf{W}^{\prime} \mathbf{R}^{-1} \mathbf{Z} & \mathbf{W}^{\prime} \mathbf{R}^{-1} \mathbf{W}+\mathbf{I} \otimes \mathbf{P}_{0}^{-1}
\end{array}\right]} \\
& \times\left[\begin{array}{c}
\hat{\mathbf{b}} \\
\hat{\mathbf{a}} \\
\hat{\mathbf{p}}
\end{array}\right]=\left[\begin{array}{c}
\mathbf{X}^{\prime} \mathbf{R}^{-1} \mathbf{y} \\
\mathbf{Z}^{\prime} \mathbf{R}^{-1} \mathbf{y} \\
\mathbf{W}^{\prime} \mathbf{R}^{-1} \mathbf{y}
\end{array}\right],
\end{aligned}
$$

where $\mathbf{y}$ is the vector of observations; $\mathbf{X}, \mathbf{Z}$, and $\mathbf{W}$ are the incidence matrices for the fixed (b), additive genetic random regression coefficients (a), and permanent environmental random regression coefficients (p), respectively; $\mathbf{A}$ is the additive genetic numerator relationship matrix based on pedigree information; and $\mathbf{I}$ is an identity matrix. $\mathbf{G}_{0}$ and $\mathbf{P}_{0}$ are the (co)variance matrices of the additive genetic and permanent environmental random regression coefficients, respectively; and $\mathbf{R}$ is the (co)variance matrix of the residual. Several studies have shown that better goodness of fit can be achieved assuming different residual variances for different periods or time intervals (e.g., Pereira et al., 2013; Flores and van der Werf, 2015).

Similar to single-record traits, the variance components of a RRM can be estimated using different methods described in the literature. Currently, the most used methods are REML (e.g., Ghiasi and Carabaño, 2018; Sanchez et al., 2018) and Bayesian (e.g., Kheirabadi, 2018; Nustad et al., 2018) methods. Considering the REML estimation method, the model assumptions for the model shown in [1] can be described as

$$
\mathrm{E}[\mathbf{y}]=\mathbf{X b}
$$

and

$$
\operatorname{Var}\left[\begin{array}{l}
\mathbf{a} \\
\mathbf{p} \\
\mathbf{e}
\end{array}\right]=\left[\begin{array}{ccc}
\mathbf{A} \otimes \mathbf{G}_{\mathbf{0}} & \mathbf{0} & \mathbf{0} \\
\mathbf{0} & \mathbf{I} \otimes \mathbf{P}_{\mathbf{0}} & \mathbf{0} \\
\mathbf{0} & \mathbf{0} & \mathbf{R}
\end{array}\right],
$$

where $\mathbf{e}$ is the vector of residuals, and all other terms were previously defined in [2]; RRM imply different additive genetic and permanent environmental variances over time, because $\mathbf{G}_{0}$ and $\mathbf{P}_{0}$ contain the variances and covariances for the coefficients of the used function. The genetic $(\Sigma)$ and environmental $(\Phi)$ (co)variance matrices for time points can be obtained as follows (assuming the same function for both factors):

$$
\boldsymbol{\Sigma}=\mathbf{T} \mathbf{G}_{0} \mathbf{T}^{\prime} \text { and } \boldsymbol{\Phi}=\mathbf{T} \mathbf{P}_{0} \mathbf{T}^{\prime},
$$

where $\mathbf{T}$ is a matrix of independent covariates for all time points (e.g., ages or DIM) associated with the function used. Consequently, RRM can provide estimates of the genetic parameters and EBV for all analyzed time points. The vector of breeding values $\left(\mathbf{E B V}_{\mathrm{j}}\right)$ of animal j, including all analyzed times, can be obtained as follows

$$
\mathbf{E B V}_{\mathrm{j}}=\mathbf{T} \hat{\mathbf{a}}_{\mathrm{j}}
$$

where $\hat{\mathbf{a}}_{\mathrm{j}}$ is the vector of EBV for the covariance function coefficients for the animal $\mathrm{j}$.

Besides the RRM, several other models or methods can be used to analyze longitudinal data taking into account all repeated records. Examples are the character process model (e.g., Pletcher and Geyer, 1999; David et al., 2007), the structured antedependence model (e.g., Jaffrézic et al., 2004; Zhao et al., 2005), the dynamic linear model (e.g., Forni et al., 2009; Das et al., 2011), and covariance functions. Due to a common misunderstanding regarding covariance functions and RRM, 
the next section aims to summarize the comparison between them.

\section{Covariance Functions}

Covariance functions are used to describe covariance among records that are measured at different time points or ages (Meyer and Hill, 1997). In brief, covariance functions can reduce the rank of the covariance matrix such that they are still equivalent to covariance matrices for traits with many longitudinal records. Several different covariance structures account for covariances among random correlated effects of repeated records, such as autoregressive, compound symmetry, and unstructured (the most complex one; Sawalha et al., 2005). Additionally, several functions used in RRM to model the trajectory of genetic and environmental effects over time can be used under a covariance function framework.

The first-order autoregressive covariance structure has only one additional parameter compared with the simple repeatability model, which implicitly assumes a compound symmetry structure, and allows for nonconstant covariances (Wade and Quaas, 1993). Harville (1979) and Quaas et al. (1984) proposed the use of an autoregressive structure to model covariance for random effects of repeated measures in animal breeding. Carvalheira et al. (1998), comparing genetic parameters estimated with models assuming or not an autoregressive covariance structure among permanent environmental effects within a lactation, reported that the autoregressive covariance structure for permanent environmental effects within lactation was effective for partitioning total variance and removing noise that would otherwise be confounded with genetic effects.

The coefficients of the covariance functions can be estimated directly from the data set using REML (Meyer and Hill, 1997) or the generalized least squares method (Kirkpatrick et al., 1990). However, if the same functions are used, models based on covariance functions are equivalent to RRM, as shown by Meyer and Hill (1997) and Van Der Werf et al. (1998). Models based on covariance functions and RRM can be computationally demanding, because they require appropriate modeling of the trajectories of genetic and environment effects, especially in the case of multiple-trait analysis.

\section{Multiple-Trait RRM}

The first genetic evaluation using multiple-trait RRM and the first multiple trait estimates of covariance components generated from multiple-trait RRM were presented by Jamrozik et al. (1997c) and Jamrozik et al. (1998b), respectively. In multiple-trait RRM, the coefficients for the chosen polynomials are estimated to explain the variation of more than one trait simultaneously over time.

The same model given in [1] can be described under a multiple-trait approach considering $N$ traits, as follows:

$$
\begin{gathered}
\mathbf{y}=\mathbf{X b}+\mathbf{Z} \mathbf{a}+\mathbf{W} \mathbf{p}+\mathbf{e}, \\
{\left[\begin{array}{l}
\mathbf{y}_{1} \\
\mathbf{y}_{2} \\
\vdots \\
\mathbf{y}_{N}
\end{array}\right]=\left[\begin{array}{cccc}
\mathbf{X}_{1} & \mathbf{0} & \cdots & \mathbf{0} \\
\mathbf{0} & \mathbf{X}_{2} & \cdots & \mathbf{0} \\
\vdots & \vdots & \ddots & \vdots \\
\mathbf{0} & \mathbf{0} & \cdots & \mathbf{X}_{N}
\end{array}\right]\left[\begin{array}{l}
\mathbf{b}_{1} \\
\mathbf{b}_{2} \\
\vdots \\
\mathbf{b}_{N}
\end{array}\right]+\left[\begin{array}{cccc}
\mathbf{z}_{1} & \mathbf{0} & \cdots & \mathbf{0} \\
\mathbf{0} & \mathbf{Z}_{2} & \cdots & \mathbf{0} \\
\vdots & \vdots & \ddots & \vdots \\
\mathbf{0} & \mathbf{0} & \cdots & \mathbf{Z}_{N}
\end{array}\right]\left[\begin{array}{l}
\mathbf{a}_{1} \\
\mathbf{a}_{2} \\
\vdots \\
\mathbf{a}_{N}
\end{array}\right]} \\
+\left[\begin{array}{cccc}
\mathbf{W}_{1} & \mathbf{0} & \cdots & \mathbf{0} \\
\mathbf{0} & \mathbf{W}_{2} & \cdots & \mathbf{0} \\
\vdots & \vdots & \ddots & \vdots \\
\mathbf{0} & \mathbf{0} & \cdots & \mathbf{W}_{N}
\end{array}\right]\left[\begin{array}{l}
\mathbf{p}_{1} \\
\mathbf{p}_{2} \\
\vdots \\
\mathbf{p}_{N}
\end{array}\right]+\left[\begin{array}{l}
\mathbf{e}_{1} \\
\mathbf{e}_{2} \\
\vdots \\
\mathbf{e}_{N}
\end{array}\right],
\end{gathered}
$$

where $\quad \mathbf{y}=\left[\begin{array}{llll}\mathbf{y}_{1} & \mathbf{y}_{2} & \ldots & \mathbf{y}_{N}\end{array}\right]^{\prime}, \quad \mathbf{b}=\left[\begin{array}{llll}\mathbf{b}_{1} & \mathbf{b}_{2} & \ldots & \mathbf{b}_{N}\end{array}\right]^{\prime}$, $\mathbf{a}=\left[\begin{array}{llll}\mathbf{a}_{1} & \mathbf{a}_{2} & \ldots & \mathbf{a}_{N}\end{array}\right]^{\prime}, \quad \mathbf{p}=\left[\begin{array}{llll}\mathbf{p}_{1} & \mathbf{p}_{2} & \ldots & \mathbf{p}_{N}\end{array}\right]^{\prime}, \quad$ and $\mathbf{e}=\left[\begin{array}{llll}\mathbf{e}_{1} & \mathbf{e}_{2} & \ldots & \mathbf{e}_{N}\end{array}\right]^{\prime}$ are the vectors of phenotypic records, fixed effects, additive genetic, permanent environmental, and residual effects, respectively, sorted by trait (from trait 1 to $N$ ). Hence, $\mathbf{y}_{\mathrm{i}}$ is the vector of phenotypic records for the $i$ th trait, $\mathbf{b}_{\mathrm{i}}$ is the vector of fixed effects affecting the $i$ th trait, $\mathbf{a}_{\mathrm{i}}$ is the vector of additive genetic random regression coefficients for the animal effect on the $i$ th trait, $\mathbf{p}_{\mathrm{i}}$ is the vector of random regression coefficients for permanent environment effects on the $i$ th trait, and $\mathbf{e}_{\mathrm{i}}$ is the vector of residuals for the $i$ th trait.

Multiple-trait RRM represent a powerful tool for joint genetic evaluation of several longitudinal traits. In brief, multiple-trait RRM ensure the advantages of multiple-trait analyses in relation to single-trait analyses, such as increased accuracy of EBV (Boligon et al., 2011). However, one specific advantage of multiple-trait RRM over single-trait RRM is the possibility to estimate genetic correlations between different traits over time, which may allow the identification of the most feasible time periods to exploit indirect selection and correlated genetic responses aiming to improve genetic gain (Oliveira et al., 2016). Multiple-trait RRM account for changes in traits over time due to the existing covariance between random regression coefficients of different traits, which are calculated over time. Thus, time changes can be accounted for; for example, in the additive genetic effects of each animal. For instance, Tsuruta et al. (2004) evaluated genetic correlations between different traits over time in Holstein cattle, using 
random regression coefficients for the additive genetic effects of each animal over the birth years. Successful applications of multiple-trait RRM to perform joint genetic analysis have been reported in beef cattle (e.g., Santana et al., 2015, 2018), buffalo (e.g., Borquis et al., 2013), goats (e.g., Brito et al., 2018), and fish (e.g., Zhao et al., 2018).

Until recently, the majority of studies performing genetic evaluations based on multiple-trait RRM had used the same function to model all traits; however, Meyer and Hill (1997) commented that, in some cases, it might be desired to fit different functions for different traits. Thus, a study in dairy goats showed that it is possible to combine different functions to describe different traits in the same multiple-trait RRM analysis (Oliveira et al., 2016). Those authors reported that using different functions to model different traits might help to achieve a better fit for each trait, which can improve the accuracy of EBV and genetic parameter estimates. Application of multiple-trait RRM has become even more flexible in terms of combining different functions under the same model. A study in dairy cattle reported the possibility of using different functions to describe the fixed and random effects of each trait, as well as using different functions for different traits, under the same multiple-trait RRM (Oliveira et al., 2017a). In contrast to those authors, Jamrozik et al. (2001) suggest that the same function should be used to describe the random genetic and environmental effects of a trait, and that the selection of the function to describe the lactation curve should be determined by the goodness of fit at the phenotypic level.

\section{Comparing Alternative Functions to Model Longitudinal Trajectory}

The first comparison of alternate functions to be used in RRM for TDMY was published by Jamrozik et al. (1997a). In the recent years, several studies have compared different functions in RRM for genetic analysis in various livestock species. For example, Bignardi et al. (2011) analyzed TDMY of Brazilian Holsteins and compared the use of Legendre orthogonal polynomials (Kirkpatrick et al., 1990) and B-spline functions (de Boor, 1980; Meyer, 2005) with the functions proposed by Ali and Schaeffer (1987) and Wilmink (1987). In summary, Bignardi et al. (2011) concluded that RRM using B-splines and Legendre polynomials are more adequate to describe the covariance structure of the data. Studying Canadian Holsteins, Bohmanova et al. (2008) found smaller prediction errors and higher stability of EBV by using spline functions compared with Legendre polynomials, which was in agreement with Bouallegue et al. (2015). This may be related to the fact that changes in traits over DIM or age of animals do not occur linearly but are more intense in early stages. Therefore, methods based on parametric functions or polynomial functions, such as Legendre polynomials, may not fit such abrupt changes well. In this context, splines can be advantageous, as they use knots to connect differently shaped segments (de Boor, 1980). In summary, splines are a type of segmented regression in which the curve is divided into different segments joined by knots, such that each segment can be modeled by a different polynomial order (de Boor, 1980). Meyer (2005) estimated genetic parameters in beef cattle using linear, quadratic, and cubic splines, and found that models fitting quadratic splines were better, because they were more flexible than linear splines and less computationally complex than cubic splines. In contrast, Pereira et al. (2013) concluded that, despite the fact that linear splines provided the smallest sum of residual variances over the lactation, RRM based on Legendre polynomials provide the best fit (according to the deviance information and Bayesian information criterion) and should be used to describe variations in milk yield of Brazilian Gyr cattle. It is important to note that all these studies have used models with fixed herd-test-day effects, which may have generated some biases, as discussed earlier in the Random Regression Models section.

For dairy goats, studies using spline functions (León et al., 2012; Thepparat et al., 2015) and parametric functions (e.g., Ali and Schaeffer's function; in González-Peña et al., 2012) to model the lactation curve have shown equal or better fit than RRM based on Legendre polynomials. For beef cattle, the majority of studies using spline functions analyzed growth traits (Speidel et al., 2010). In general, these studies show that RRM based on spline functions are an alternative to RRM based on Legendre polynomials, because similar EBV estimates are obtained using both functions (e.g., Iwaisaki et al., 2005; Boligon et al., 2011). For sheep, Zamani et al. (2016) concluded that using RRM based on B-splines and Legendre polynomials to fit growth curves generated similar estimates of variance components as ratios to total phenotypic variance, but the models with Legendre polynomials showed better fitting properties.

Even though some divergent conclusions have been made about the best functions to use in RRM across different studies and traits, the results indicate that, in practice, the same bulls would be selected by both RRM using Legendre polynomials and spline functions (Pereira et al., 2013). Moreover, Jamrozik and Schaeffer (2002) showed that different comparison methods ranked RRM based on different functions differently. Thus, to define which function should be used in each 
case, advantages and disadvantages of each should be considered. Nonorthogonal polynomials could produce coefficients that are highly correlated and this may yield computational problems during estimation or solving of the MME. Thus, orthogonal polynomials have been preferred among the polynomial functions, because they give the lowest correlations among the estimated regression coefficients. The RRM based on Legendre polynomials tend to consider fewer coefficients than corresponding analysis using B-spline functions (Meyer, 2005), which may allow using more parsimonious models. However, RRM based on Legendre polynomials usually generate inflated variances at the extremes of the lactation curve, as demonstrated by Misztal (2006). An alternative to avoid these unstable predictions and forecasts, especially when using high-order Legendre polynomials, is the use of the autoregressive functions (e.g., Carvalheira et al., 1998). Analysis using RRM based on spline functions has the advantage of faster convergence over Legendre polynomials, which may be because spline coefficients are sparser than their polynomial counterparts (Misztal, 2006). However, one of the most important questions when using spline functions is related to the number and location of knots (points at which independent linear segments are connected), which should be defined before the analysis (Jamrozik et al., 2010) or determined by a nonlinear procedure. Although RRM based on parametric functions (e.g., Ali and Schaeffer and Wilmink) have shown poor fit compared with Legendre and spline functions in the majority of studies, analyses based on these functions seem to have faster convergence than analyses based on polynomial functions, considering the same number of parameters when the number of observations is small (Oliveira et al., 2016).

\section{Applications of RRM}

In Research. The potential for practical applications of RRM was presented by Schaeffer and Dekkers (1994). Random regression models became more sophisticated over time through the development of alternative functions and advances in model structures. Indeed, RRM have been used in a wide range of research areas, including genotype by environment interaction $(\mathbf{G} \times \mathbf{E}$; e.g., Calus and Veerkamp, 2003; Oliveira et al., 2018a), multiple-trait analysis combining different functions to describe each trait (Oliveira et al., 2016, 2017a), and categorical traits (e.g., Averill et al., 2004; Oliveira et al., 2017b). Brügemann et al. (2013) showed that a threshold RRM could be applied to study genetic effects on binary traits. Yin et al. (2012) analyzed normally distributed and categorical traits in organic and low-input dairy cattle herds and showed that RRM can be applied to data from small herds with a limited number of repeated measurements per cow.

The popularity of RRM has increased substantially in animal breeding research over the past years, and RRM have been considered the method of choice to genetically evaluate longitudinal traits in various livestock species, including dairy cattle (e.g., Kheirabadi, 2018; Padilha et al., 2018), beef cattle (e.g., Oliveira et al., 2018a), sheep (e.g., Saghi et al., 2018), goats (e.g., Brito et al., 2018), horses (e.g., Bartolomé et al., 2018), swine (e.g., Huynh-Tran et al., 2017), poultry (e.g., Miyumo et al., 2018), quail (e.g., Mota et al., 2018a), and fish (e.g., Zhao et al., 2018).

In Industry. Australia was the first country to use TDMY records in 1984 in the official genetic evaluations of dairy species, adjusting the accumulated yield for the test-day effect (Powell and Norman, 2006). However, the first country to implement RRM as the official model for genetic evaluation of animals was Canada, in 1999. The multiple-trait RRM initially used 12 traits (milk, fat, and protein yields and SCS in each of the first 3 lactations) and was based on orthogonal Legendre polynomials. The RRM initially adopted by Canada are detailed in Schaeffer et al. (2000).

Canada is currently using 2 multiple-trait RRM, one to analyze milk, fat, and protein yields in each of the first 3 lactations and another to analyze SCS in the first 3 lactations. The decision to analyze SCS separately from production traits was officially made by the Canadian Dairy Network (Guelph, ON, Canada) in 2016 to improve the stability of published SCS proofs (CDN, 2016). Both models, for production traits and SCS, include the effect of herd-test day-parity and DIM within lactation (from 5 to $305 \mathrm{~d}$ ), and regression curves for year-season-region-parity-age of calving as fixed effect, the effect of herd-year of calving, additive genetic and permanent environment as random effects. All regressions are modeled through fourth-order Legendre orthogonal polynomials (i.e., 5 covariates), and both models account for heterogeneity of residual variance, assuming 10 classes of residual variance for each parity (Interbull, 2018).

Many other countries have adopted RRM as the official model for genetic evaluation in dairy cattle, including Australia, Belgium, Croatia, Czech Republic, Denmark-Finland-Sweden, Estonia, Germany-AustriaLuxembourg, Italy, Japan, Latvia, Lithuania, New Zealand, Poland, Republic of Ireland, Slovak Republic, Switzerland, the Netherlands, and United Kingdom, as reported by Interbull (2018). Specifically in the United States, TDMY records have been collected since 1905 for herd management purposes; however, until 1990, only 305-d yields were used for national genetic evaluations (Wiggans and Goddard, 1997). Although TDMY 
records have been available for a long time in the United States, a patent applied for by Robert W. Everett from Cornell University in 1993 forestalled the use of RRM in the United States except for regional and unofficial evaluations performed by the patent holders (Powell and Norman, 2006). Thus, even though RRM are still not currently used for official genetic evaluations in the United States, the application status of this patent expired in February 2019 (https://patents.google.com/ patent/US5351644A/en), which may now promote the use of RRM in the United States in the near future.

One of the concerns that US researchers may have about the use of RRM in official genetic evaluations is the size of the US data set. In this context, Aguilar et al. (2010b) used RRM to investigate the genetic trends of milk yield under heat stress in US dairy cattle, using all data available at that time (which included 9,326,754 animals in the pedigree file and 5,402,484 cows with records collected from 1993 to 2004).

However, the current amount of test-day data available, about 15 yr later, may be much larger, which can hamper efficient predictions using RRM. Different computational algorithms and alternatives are being developed to allow efficient evaluations using RRM, as noted in Oliveira et al. (2019a). In addition, one option to reduce computational demand is to reduce the data size by data truncation, as mentioned by Lourenco et al. (2014b).

\section{Implementation of RRM Compared with Other Statistical Approaches}

Among the advantages of using RRM to analyze longitudinal data in genetic evaluations is the fact that RRM allow for a more precise adjustment for environmental effects in the course of the phenotypic curve, because RRM account for time-dependent variation over the lactation (Swalve, 2000). As previously discussed, another advantage of RRM is that they may require the estimation of fewer parameters than other methodologies (e.g., multiple-trait models). In addition, RRM do not require records to be measured at the same time in all individuals (i.e., all phenotypic information can be used for the genetic analyses); consequently, it does not require a minimum number of records per animal (Schaeffer, 2004). However, because there is no requirement regarding the minimum number of records per animal, unstable predictions may occur if only a few animals have several records and several animals have very few or only one record, especially if high polynomial degrees or complex functions are used. On the other hand, data originated from sensors and automated devises for measuring new traits (e.g., feed efficiency, methane emission, behavior), which can have thousands of time points, might generate new opportunities to use RRM in genetic evaluations.

Random regression models also enable accounting for changes in genetic variation in production over time, because covariance components can be estimated for all time points. Thus, genetic parameters and EBV can be estimated for numerous time points, including times in which phenotypes were not recorded but are within the measurable period range (White et al., 1999). In the dairy cattle context, RRM allow the prediction of the shape of lactation curves in the genetic evaluations and, therefore, genetically select animals with more desirable lactation curve patterns. Lactation persistency has been included in the selection index of some countries (i.e., Canada) in an attempt to select on the lactation curve pattern (Interbull, 2018). However, inferences about the complete lactation curve cannot be made exclusively based on lactation persistency. Thus, one idea to help select animals with a desirable lactation pattern is to develop selection indexes to combine EBV from different DIM (or different lactation stages), which will reflect how close the lactation pattern of an animal is to the desirable lactation pattern for a production system. The selection of animals based on the complete lactation curves (using an index such as the one mentioned above) takes into account lactation biology and the physiological implications of different lactation curve patterns, which may help to decrease the energy deficiency experienced during early and peak lactation, as suggested by Jamrozik et al. (1998a) and Oliveira et al. (2019b).

Comparing EBV predicted by random regression and repeatability models, several authors have concluded that total genetic merit is more accurately predicted when using RRM (e.g., Andonov et al., 2013; Khanzadeh et al., 2013). Compared with the use of a linear model to analyze accumulated yield, using RRM based on TDMY records avoids the use of extended records for culled cows and for lactations in progress, as well as the use of projection (for the entire lactation) factors, which can remove the errors in estimating the accumulated yield from the genetic analysis (Jensen, 2001). In agreement, Kistemaker (1997) reported that EBV from RRM are more accurate than EBV from accumulated 305-d models, using simulated data. However, even though EBV from RRM are more accurate, sometimes the gain in accuracy may not be worth it when considering the higher complexity of RRM, especially when RRM predictions are encapsulated into 1 or 2 values used to select the animals.

Another limitation of RRM relates to the large amount of data to be analyzed, because several measurements are recorded for the same individual (Swalve, 2000; Jensen, 2001). Thus, the amount of data stored 
to be used in RRM is much greater than that with other methodologies. The concern about the number of parameters to be estimated is mainly related to the computational demand; that is, in the difficulty achieving appropriate convergence in the MME (Swalve, 2000). Computational algorithms to evaluate large data sets based on complex models have been developed (e.g., preconditioned conjugate gradient algorithm; Strandén and Lidauer, 1999; Tsuruta et al., 2001), which allow iteration on data using blocks of different size as preconditioner to facilitate a joint estimation of the regression coefficients (Oliveira et al., 2019a). Furthermore, over the past decades, there has been a great advancement in computing resources and these computing limitations might be partially overcome in the very near future.

Concerns about the amount of data and computational demand required by RRM analysis are even more important in the genomics era, in which a large number of genetic markers (e.g., SNP) are included in the analysis to predict the realized relationship among individuals. Thus, to enable the implementation of genome-wide selection (GWS; Meuwissen et al., 2001) based on large data sets and complex models, such as RRM, several methodologies have been developed to speed up genomic analysis, such as the algorithm for proven and young (APY; Misztal et al., 2015; Masuda et al., 2016). In summary, the APY allows the inversion of the genomic matrix for millions of genotyped animals using a reduced number of iterations (Misztal et al., 2015), because genomic EBV (GEBV) of noncore animals (e.g., young genotyped animals) are conditioned on GEBV of core animals (e.g., their ancestors). Masuda et al. (2016), evaluating the computational costs of the APY algorithm for analyzing a nonlongitudinal trait for 2 million genotyped animals, noted that the computing time to invert the genomic matrix (assuming 10,000 core animals) would be only $4.5 \mathrm{~h}$. However, for longitudinal traits, no studies using APY and RRM were found in the literature. Without using APY, Oliveira et al. (2019a) reported that an initial test of the BLUP90IOD program based on a multipletrait RRM including more than 72 million records for 9 milk production traits and all genotypes available for the Holstein breed in Canada needed approximately $4 \mathrm{~d}$ to achieve the convergence criteria. Therefore, computational demand will most likely not be a major bottleneck for implementation of genomic selection of longitudinal traits in the near future.

\section{AN OVERVIEW OF GENOMIC SELECTION}

Genome-wide selection, which started with the seminal studies of Nejati-Javaremi et al. (1997) and
Meuwissen et al. (2001), has been implemented in various livestock breeding schemes and is considered a landmark in modern livestock breeding programs (e.g., Boichard et al., 2016; Samorè and Fontanesi, 2016; Wiggans et al., 2017). In the dairy industry, young bulls have been selected based on their genomic information since the first genomic PTA were officially published in the United States and Canada in 2009 (Masuda et al., 2018). Including genotypic information in the evaluations has increased the accuracy of breeding values in the range of 30 to $70 \%$ (VanRaden et al., 2009; Harris and Johnson, 2010) and the rates of genetic gain per year from 50 to $100 \%$ for productive traits (García-Ruiz et al., 2016). Especially for selection of candidates at a young age, the increase in accuracy enables a reduction in the generation interval and consequently, increases the genetic gain per time unit. In species with long generation intervals, such as dairy cattle, GWS reduces the costs compared with traditional progeny testing schemes (Schaeffer, 2006; König et al., 2009; VanRaden et al., 2009), which translates to saving millions of dollars worldwide every year.

The majority of livestock breeding programs implemented GWS initially based on a multiple-step genomic BLUP (GBLUP) approach, as reported by Interbull (2017a) for dairy cattle. The prediction of GEBV based on the multiple-step GBLUP requires the prediction of traditional EBV and the subsequent use of pseudoobservations, typically either daughter yield deviations or deregressed EBV (dEBV). Thereafter, the pseudoobservations are used as pseudo-phenotypes in a subsequent step to estimate direct genomic values (DGV; Gao et al., 2013; Koivula et al., 2015; Winkelman et al., 2015). In general, dEBV are more often used than daughter yield deviations because of their easy availability, especially when the training population is based on genotypes from different countries (Mäntysaari et al., 2011). Several methods have been suggested to estimate dEBV, especially for nonlongitudinal traits, such as those in Garrick et al. (2009), VanRaden et al. (2009), and Wiggans et al. (2011).

Usually, the DGV from the GBLUP method are estimated based on a linear model, where an overall mean is assumed as a fixed effect and the marker effects are assumed as random. In the MME, the main difference is that the numerator relationship matrix $(\mathbf{A})$ is replaced by a genomic relationship matrix $(\mathbf{G})$. In brief, $\mathbf{G}$ reflects the observed identical-by-state relationship between genotyped individuals and it can be created in different ways (e.g., VanRaden, 2008; Makgahlela et al., 2013). The same DGV estimated by the GBLUP method can be obtained by using SNP estimates generated by the equivalent marker effects model (SNPBLUP; Koivula et al., 2012). To increase the accuracy 
and reduce the bias of genomic predictions, the DGV are usually blended to the parent average to generate the GEBV (VanRaden et al., 2009; Patry and Ducrocq, 2011).

One of the main concerns about the use of multiplestep GBLUP is the current underestimation of traditional EBV for young bulls, because their genomic preselection is usually not accounted for in traditional genetic evaluations (Patry and Ducrocq, 2011). Thus, as EBV are generally biased, they can lead to inaccurate GEBV. To account for the genomic preselection and therefore, predicting more accurate and less biased GEBV, various studies have suggested the simultaneous combination of phenotypic records, pedigree and genomic information in a method known as single-step GBLUP (ssGBLUP; Misztal et al., 2009; Aguilar et al., 2010a; Christensen and Lund, 2010).

Compared with the multiple-step GBLUP approach, ssGBLUP seems to simplify the procedure, because only one analysis is performed and the same statistical model used in genetic evaluations can be assumed (Lourenco et al., 2014a; Misztal et al., 2014). Moreover, ssGBLUP avoids the estimation of deregressed EBV (or daughter yield deviations) used in the multiple-step GBLUP analysis. In general, the use of actual phenotypes in the ssGBLUP (instead of pseudo-phenotypes) may avoid estimation errors and may help to account for the genomic preselection of young bulls, as all information is combined simultaneously (Patry and Ducrocq, 2011; Masuda et al., 2018). In addition, ssGBLUP eliminates the problem of double-counting information found in multiple-step evaluations when including genotypes from bulls and their daughters in the training population, when improper methods of EBV deregression are used (Uemoto et al., 2017; Oliveira et al., 2019c).

In general, ssGBLUP replaces the $\mathbf{A}$ matrix used in the MME by an $\mathbf{H}$ matrix that combines the $\mathbf{A}$ and G relationship matrices (Misztal et al., 2009; Legarra et al., 2014). Usually $\mathbf{H}$ is computationally demanding to create; however, its inverse has a simple structure (Aguilar et al., 2010a; Christensen and Lund, 2010):

$$
\mathbf{H}^{-1}=\mathbf{A}^{-1}+\left[\begin{array}{cc}
\mathbf{0} & \mathbf{0} \\
\mathbf{0} & \tau\left(\alpha \mathbf{G}+\beta \mathbf{A}_{22}\right)^{-1}-\omega \mathbf{A}_{22}^{-1}
\end{array}\right],
$$

where $\mathbf{G}$ is the genomic relationship matrix; $\mathbf{A}^{-1}$ is the inverse of the traditional relationship matrix $(\mathbf{A}), \mathbf{A}_{22}$ is the section of $\mathbf{A}$ related to genotyped animals; and $\mathbf{A}_{22}^{-1}$ is the section of $\mathbf{A}^{-1}$ related to genotyped animals. The $\alpha$ and $\beta$ parameters are used to make $\mathbf{G}$ invertible or nonsingular (Koivula et al., 2015), and $\tau$ and $\omega$ are parameters used to account for the reduced genetic variance and for different depths of pedigree, respec- tively, to make $\mathbf{G}^{-1}$ and $\mathbf{A}_{22}^{-1}$ compatible (Misztal et al., 2017). In this context, the compatibility between $\mathbf{G}^{-1}$, $\mathbf{A}^{-1}$, and $\mathbf{A}_{22}^{-1}$ is also related to the completeness of the pedigree and inbreeding (Misztal et al., 2017). Several studies have shown that adjusting $\mathbf{G}^{-1}$ toward their expected values in $\mathbf{A}_{22}^{-1}$ decreases the scaling problem, which can improve the accuracy and simultaneously reduce the bias in ssGBLUP evaluations (e.g., Vitezica et al., 2011; Christensen et al., 2012).

Even though RRM are routinely used in genetic evaluations of longitudinal traits in several countries (Interbull, 2018), GEBV are usually generated for the accumulated yield (e.g., Winkelman et al., 2015; Jenko et al., 2017) or for phenotypes taken at specific times (e.g., Martínez et al., 2017; Campos et al., 2018), which does not allow selecting animals for the complete curve pattern. Among the reasons why RRM are not combined with genomic information in official evaluations is the fact that selection decisions made on components of RRM may be less accurate than those based on accumulated production, which may reduce the possible gains due to the inclusion of genomics compared with genomic analyses of accumulated production (Oliveira et al., 2019b). In dairy cattle, the fact that Interbull currently requires only one EBV or GEBV per trait to perform MACE (Interbull, 2017b) has also been a limiting factor for the countries that participate in international evaluations, as extra calculations would be needed to summarize the predictions. To make inferences about the trajectory of the curves, some studies have proposed estimating GEBV for curve parameters (coefficients) calculated in a first step (e.g., Lázaro et al., 2017). However, this approach still requires extra steps to estimate the EBV or GEBV exchanged by Interbull, and it gives limited inferences about the pattern of the phenotypic curve, which might not have biological interpretation in some cases. Thus, including genomic information to evaluate longitudinal traits using RRM would be a more desirable alternative to yield more accurate selection and culling decisions, even though more research is still needed to define the best way to implement RRM predictions in animal breeding programs.

\section{GENOMIC PREDICTIONS BASED ON RRM}

Genomic predictions for various time points can be simultaneously done using RRM, which enables selection of breeding animals based on the complete pattern of the production curve using genomic information. Two main approaches have been described in the literature to combine genomic information and RRM to estimate daily GEBV: (1) using 2-step GBLUP, where 
both steps are based on RRM (Oliveira et al., 2019b); and (2) using ssGBLUP based on RRM (Koivula et al., 2015; Jattawa et al., 2016; Baba et al., 2017; Kang et al., 2018; Oliveira et al., 2019a).

In the first approach, EBV for each time point are estimated based on RRM, and then EBV are deregressed and used as pseudo-phenotypes to estimate the DGV for each time point, based on a second random regression model (Oliveira et al., 2019b). In brief, the first random regression model used by those authors is similar to that in equation [1], where several fixed and random effects are fitted. However, in the second random regression model, only a fixed regression (mean) and the genomic random regression coefficients were fitted. Thus, the MME created for the second-step was simplified (i.e., there was no permanent environmental effect and homogeneity of residual variances was assumed). Additionally, the $\mathbf{A}$ matrix was replaced by a $\mathbf{G}$ matrix in the MME for RRM as in equation [2].

Oliveira et al. (2019b) reported that using RRM in both steps of a 2-step GWS produces moderately accurate GEBV over the lactation but that the observed accuracy of GEBV over the lactation curve is, in general, lower than the observed accuracy for 305-d accumulated yield. The authors related those findings to the fact that it is more difficult to predict GEBV for each day in milk than for accumulated yield, which could have resulted in a larger total amount of estimation error generated by the RRM compared with the use of the 305-d accumulated model. Nonetheless, the authors reported higher accuracy for GEBV compared with parent average for all analyzed traits.

Deregression methods for longitudinal traits are complex, because they need to take into account the covariance between time points in the deregression process. Thus, a recent study based on real Jersey cattle data compared the performance of 3 different deregression methods that are usually applied to nonlongitudinal traits (i.e., Garrick et al., 2009; VanRaden et al., 2009; Wiggans et al., 2011) in the deregression of longitudinal traits for dairy cattle (Oliveira et al., 2018b). The authors concluded that deregressing longitudinal EBV using deregression methods for nonlongitudinal traits is feasible and that the methods suggested by VanRaden et al. (2009) and Wiggans et al. (2011) yielded more accurate and less biased genomic predictions than the method suggested by Garrick et al. (2009). However, using dEBV does not avoid the preselection problem in multiple-step evaluations (Patry and Ducrocq, 2011; Masuda et al., 2018), which may hamper the success of genomic prediction.

For genomic predictions based on ssGBLUP, the same random regression model used in genetic evaluations can be used (e.g., equation [1]). Thus, the MME created for ssGBLUP is similar to the MME shown in equation [2], with the only difference being that the A matrix is replaced by the $\mathbf{H}$ matrix, constructed as shown in equation [8]. The ability to use the same statistical models when incorporating genomic information via ssGBLUP is a great advantage of the ssGBLUP method (Lourenco et al., 2014a; Misztal et al., 2014). This feature might explain the higher number of studies using ssGBLUP based on RRM (Koivula et al., 2015; Jattawa et al., 2016; Baba et al., 2017; Kang et al., 2018; Oliveira et al., 2019a) compared with studies using the multiple-step approach (Oliveira et al., 2019b).

In general, studies using ssGBLUP based on RRM concluded that this approach provides higher accuracy and less biased GEBV compared with other methods (Koivula et al., 2015; Jattawa et al., 2016; Kang et al., 2018). However, Oliveira et al. (2019a) pointed out that improvements in computing time for the analysis of large data sets may be needed and desirable. In addition, Koivula et al. (2015) and Oliveira et al. (2019a) showed that there is a great need to identify the best option to combine $\mathbf{A}^{-1}$ and $\mathbf{G}^{-1}$. In a simulation study, Kang et al. (2017) compared the performance of ssGBLUP and multiple-step GBLUP based on RRM and reported that the ssGBLUP method achieved the highest accuracy and unbiasedness under all simulated scenarios, indicating robust prediction ability in longitudinal trait analyses. Moreover, the authors showed that ssGBLUP had better persistency of accuracy over generations than the multiple-step GBLUP method (Kang et al., 2017). One year later, Kang et al. (2018) performed an ssGBLUP evaluation using a real data set of Chinese Holsteins. The authors concluded that ssGBLUP was feasible for implementation in breeding practice, and that its prediction performance (i.e., accuracy and unbiasedness) was superior to the RRM based on BLUP and the multiple-step GBLUP. In plants, Campbell et al. (2018) showed the utility of using RRM for genomic prediction of shoot growth trajectories in rice (Oryza sativa). In summary, those authors estimated an $11.6 \%$ increase in prediction accuracy when using RRM compared with a model that fitted each time point independently. Thus, they concluded that RRM can be effectively used to improve the accuracy of genomic prediction for longitudinal traits in rice.

Another interesting application of the combination of RRM and genomic information is for investigating $\mathrm{G} \times \mathrm{E}$ interactions via reaction norms, aiming to more accurately estimate GEBV for selection candidates. Few studies report on the estimation of GEBV for animals in different environments using either a multiple-step (Silva et al., 2014) or single-step (Mota et al., 2016; Oliveira et al., 2018a) approach. In this context, Silva et al. (2014) performed a sire evaluation for total num- 
ber of pigs born and concluded that $\mathrm{G} \times \mathrm{E}$ interactions were important for the proper genomic evaluation of sires and that genomic information can increase the accuracy of selection across environments. Nonetheless, Mota et al. (2016), studying tick resistance in Hereford and Braford beef cattle, reported that genomic information does not lead to higher prediction accuracies in reaction norm models, suggesting that the benefits observed for combining genomic information and RRM are trait and species specific. Oliveira et al. (2018a) contrasted the use of traditional BLUP and ssGBLUP in reaction norms to evaluate the existence of $\mathrm{G} \times \mathrm{E}$ for yearling weight in Nellore cattle. The authors concluded that both methodologies were capable of identifying the $\mathrm{G} \times \mathrm{E}$ interaction. However, the ability to predict the animals' future performance was improved by $7.9 \%$ using ssGBLUP.

In addition to the prediction of GEBV, RRM can be used to estimate SNP effects and the variances explained by them over time in genome-wide association studies (GWAS).

\section{GWAS FOR LONGITUDINAL TRAITS}

Over the past decades, numerous GWAS have been performed using a large number of genetic markers (e.g., SNP) spread across the entire genome of the species of interest, aiming to detect genetic variants associated with a particular phenotype. The main goals of such studies were to unravel the genetic architecture and underlying biology of the traits, to develop genetic tests and personalized treatments in humans (e.g., Ghouse et al., 2018; Turner et al., 2018), and to propose more accurate genomic selection methods and breeding approaches in plants (e.g., Guo et al., 2018; Gyawali et al., 2018) and livestock species (e.g., Meng et al., 2017; Higgins et al., 2018). As previously discussed, a large number of economically important traits in livestock species are longitudinal and, like single-record traits, an increased interest in estimating the effects of genomic markers for these traits has been observed (e.g., Ning et al., 2017; Soares et al., 2017; Mota et al., 2018b). This section discusses alternatives to perform GWAS for longitudinal traits, with a focus on RRM.

Different approaches have been used to perform GWAS for longitudinal traits. Until recently, the majority of studies have converted multiple phenotypic measurements for each animal into a single estimate (e.g., average over all time points and 305-d milk yield EBV or dEBV). These (pseudo-)phenotypes are used as response variables for the GWAS analyses (e.g., Buitenhuis et al., 2014; Nayeri et al., 2016). However, various studies have shown that the additive polygenic effects of longitudinal traits are not constant during the entire phenotypic expression (e.g., growth or lactation, as exemplified by Strabel et al., 2005; Zavadilová et al., 2005; Brito et al., 2018). Furthermore, using milk production as an example, gene expression studies have indicated that the amount of RNA synthesized often varies across lactation (e.g., Bionaz and Loor, 2008), and specific genes (e.g., DGAT1) or genetic loci can be less pronounced or even reversed during the first stage of lactation (Strucken et al., 2011) or change from early to peak to late lactation (Strucken et al., 2012). Strucken et al. (2012) treated 10-d lactation intervals in the initial lactation stage and 305-d EBV as separate traits and observed significant differences in allele effects across time periods. Similarly, when studying growth traits, various studies defined each weighing time as a different trait or phenotype to perform GWAS (e.g., Snelling et al., 2010; Lu et al., 2013; Qiao et al., 2015). In chickens, Xie et al. (2012) performed GWAS for BW measured at hatching, 7, 14, 21, 28, 35, 42, 49, 56, 63, $70,77,84$, and $90 \mathrm{~d}$ of age.

Another alternative to generate pseudo-phenotypes for GWAS analyses of longitudinal traits considering the whole phenotypic trajectory is by using linear and nonlinear models, which summarize longitudinal records in a few parameters that usually have biological interpretation. These parameters are then used as phenotypes for the GWAS (or QTL detection). For instance, Rodriguez-Zas et al. (2002) used the parameters based on Morant and Gnanasakthy (1989) function to estimate the effects of a chosen set of markers on the parameters of the function and reported the presence of QTL influencing the scale and shape parameters that describe the lactation pattern. A study carried out on German Holstein cows divergently selected for milk yield used Wilmink function parameters as phenotypes (Strucken et al., 2012) and also identified SNP associated with lactation curve traits, such as lactation persistency. Later, Soares et al. (2017) proposed a multiple-trait GWAS of estimated growth curve parameters for scrotal circumference recorded over time (as an indicator of fertility traits) in Brahman cattle. Five widely used nonlinear models (i.e., Brody and Lardy, 1946; von Bertalanffy, 1957; Richards, 1959) were tested to fit scrotal circumference records (measured at 6,12 , 18, and 24 mo of age). The model parameters were used as pseudo-phenotypes for the subsequent GWAS analyses. A similar study was also performed by Crispim et al. (2015) using beef cattle growth data. An advantage of using the parameters of those functions as pseudophenotypes for the GWAS analyses is that they usually provide a direct description of a geometric property of the curve or have some biological interpretation (e.g., persistency) that can explain the underlying biology of the trait. 
Another alternative approach for GWAS of longitudinal traits is principal component analysis, in which the scores of a reduced number of principal components based on multiple variables (e.g., longitudinal records) can be used as a "single phenotype" when performing the GWAS analysis. As indicated by Macciotta et al. (2015), these model-free approaches are able to derive measures of lactation curve (or other longitudinal trait) traits without specific assumptions on data structure. For instance, Macciotta et al. (2015) performed a GWAS using the scores of the first 2 principal components from test-day records for milk yield, fat and protein percentages, and SCS as the response variables for GWAS analyses.

The use of longitudinal models in GWAS, such as random regression, allows for SNP having a heterogeneous effect across the trajectory to be characterized. Tetens et al. (2014) estimated dEBV for DMI from RRM using third-order Legendre polynomials, and the daily dEBV for DIM 11, 30, 80, 130, and 180 were used as phenotypes for GWAS. They identified interesting lactation stage-specific candidate genes and pathways. Similarly, Pryce et al. (2010) performed a GWAS for different measures of lactation persistency on primiparous Holstein and Jersey cows based on RRM.

Wang et al. (2014b) proposed a 2-step method for simultaneously testing the genetic association with multiple longitudinal traits aiming to detect pleiotropic effects in real and simulated data. In summary, the authors used a mixed effects model to estimate the random effects for each longitudinal trait in the first step, and then, in the second step, they performed a simultaneous association test. They concluded that this method can efficiently detect the pleiotropic effects on multiple longitudinal traits.

As discussed by Szyda et al. (2014), the effects of particular genes on longitudinal traits were estimated using linkage analysis by Yang, (2006), Yang and Xu (2007), Yang et al. (2007), Lund et al. (2008), and Suchocki et al. (2013). The models proposed by Yang (2006) and Yang and $\mathrm{Xu}$ (2007) incorporate time-dependent fixed effects of QTL together with a random time-dependent residual effect, but no polygenic effect was considered. Yang et al. (2007) considered a fixed QTL effect with a polygenic component approximated by cofactors. Lund et al. (2008) and Suchocki et al. (2013) estimated individual additive effect curves underlying a random QTL effect together with a random additive polygenic effect. In Szyda et al. (2014), the additive effects of candidate genes were modeled as time-dependent and populationaverage fixed effects, similar to the approach described by Yang (2006) and Yang and Xu (2007). The authors reported changes in additive effects of specific markers throughout lactation.
The SNP effects on longitudinal traits can be obtained from GEBV (e.g., Silva et al., 2014; Verardo et al., 2017; Mota et al., 2018b). For instance, Mota et al. (2018b) performed a candidate gene mapping study fitting genomic reaction norms in a single-step GWAS (ssGWAS; Wang et al., 2014a) in beef cattle, in which SNP effect patterns across environments were obtained. Howard et al. (2015) and Oliveira et al. (2018a) performed ssGWAS on the animal polynomial coefficients (modeled by Legendre polynomials) for different longitudinal traits. Previous research has used RRM to characterize the effect of individual SNP across time using either simulated (Lund et al., 2008) or real (Szyda et al., 2014) data on a small number of markers. Characterizing SNP effects across a trajectory when the data are derived from dense SNP arrays is computationally quite demanding.

Random regression-based models are currently the most sophisticated and flexible tools to perform GWAS for longitudinal traits. Das et al. (2011) proposed a method based on random regression enabling the exploitation, for instance, of additive and dominance effects and specific covariance functions to describe changes in the SNP effects over time. The authors generalized this method to a multiple-trait approach, making it even more powerful and applicable to situations involving more than one trait.

As discussed by Ning et al. (2017), RRM increase the power to detect QTL compared with accumulated phenotypes, repeatability model, and multiple-trait model in QTL mapping. They are also suitable for detection of QTL in the presence of gene by environment interactions (Lillehammer et al., 2007). Ning et al. (2017) developed 2 models based on RRM to model the time-dependent SNP effect for the GWAS analysis; that is, GWAS model treating each SNP as the covariate and GWAS model treating each SNP as the factor. The authors showed that the proposed models captured genetic differences that occurred during the analyzed time period, which increased the statistical power of QTL detection. Different from Das et al. (2011), Ning et al. (2017) divided the time-varied mean values for SNP genotypes into 2 parts, time-dependent population mean and SNP effects, instead of fitting them directly. Using simulated and real data, Ning et al. (2017) showed that the proposed methods based on longitudinal phenotypes outperformed GWAS methods that were based on deregressed proofs, regarding both control of false-positive rate and power of QTL detection. A constraint of the models proposed by Ning et al. (2017) was the computational inefficiency, because the dimension of the MME was larger than other models. Subsequently, Ning et al. (2018) proposed an alternative approach, called the rapid longitudinal GWAS 
method, also based on RRM, which uses eigen decomposition to rotate the dense phenotypic covariance matrix into a diagonal matrix, thereby transforming the complex mixed linear model into weighted least squares analysis. Using simulated data, they showed that this method can control type I errors well and has higher power than a longitudinal GWAS method that does not include time-varied additive genetic effects. As noted by the authors, the orders of Legendre polynomials will influence the performance of the proposed longitudinal GWAS model.

Strategies to perform GWAS, which can fit the timevaried marker effects and directly use the raw longitudinal records are very advantageous, as they avoid the need to generate pseudo-phenotypes. In addition, as highlighted by Rodriguez-Zas et al. (2002) and Szyda et al. (2014), stage-specific QTL might not be identified when using cumulative lactation record models because the effects of these QTL are likely to be diluted across the lactation.

Finally, if we focus on a few SNP of interest, the usual RRM can be augmented with a factor (SNP genotype) with either fixed or random regressions within each of the 3 genotypes. Either the $\mathbf{A}$ or $\mathbf{H}$ matrix can be used to model the covariance among animal additive genetic effects for genotyped animals. This would give 3 trajectories, one for each SNP genotype, which can be plotted or tested for differences from each other. This is simple and existing software could be used without substantially increasing computational time.

\section{CONCLUSIONS}

Genomic predictions for various points in time can be simultaneously done using RRM, which enables selection of breeding animals based on the complete pattern of the production curve using genomic information. Therefore, including genomic information to evaluate longitudinal traits using RRM is an alternative to yield more accurate selection and culling decisions. Moreover, RRM can be used to estimate SNP effects and the variances explained by them over time in GWAS. By analyzing marker associations over time, we are more likely to identify regions with higher effects at specific time periods, which would contribute to better explain the observed phenotypic variation in longitudinal traits. Despite all advances in applications of RRM, more research is needed to successfully combine RRM and genomic information. Future research should provide better understanding of the temporal variation of biological processes and their physiological implications underlying the longitudinal traits.

\section{ACKNOWLEDGMENTS}

The first author acknowledges the Coordenação de Aperfeiçoamento de Pessoal de Nível Superior (CAPES; Brasília, DF, Brazil) for financial support.

\section{REFERENCES}

Aguilar, I., I. Misztal, D. L. Johnson, A. Legarra, S. Tsuruta, and T. J. Lawlor. 2010a. Hot topic: A unified approach to utilize phenotypic, full pedigree, and genomic information for genetic evaluation of Holstein final score. J. Dairy Sci. 93:743-752. https://doi.org/10 .3168/jds.2009-2730.

Aguilar, I., I. Misztal, and S. Tsuruta. 2010b. Short communication: Genetic trends of milk yield under heat stress for US Holsteins. J. Dairy Sci. 93:1754-1758. https://doi.org/10.3168/jds.2009-2756.

Agyemang, K., E. C. Clapp, and L. D. Van Vleck. 1985. Variancecovariance components associated with trimester yields of milk and fat and multiple trait sire evaluation for trimester yields. J. Dairy Sci. 68:1233-1240. https://doi.org/10.3168/jds.S0022 -0302(85)80951-6.

Ali, T. E., and L. R. Schaeffer. 1987. Accounting for covariances among test day milk yields in dairy cows. Can. J. Anim. Sci. 67:637-644. https://doi.org/10.4141/cjas87-067.

Andonov, S., J. Ødegård, M. Svendsen, T. Ådnøy, M. Vegara, and G. Klemetsdal. 2013. Comparison of random regression and repeatability models to predict breeding values from test-day records of Norwegian goats. J. Dairy Sci. 96:1834-1843. https://doi.org/10 .3168/jds.2012-5910.

Auran, T. 1973. Studies on monthly and cumulative monthly milk yield records. Acta Agric. Scand. 23:189-199. https://doi.org/10 $.1080 / 00015127309433217$

Averill, T. A., R. Rekaya, and K. Weigel. 2004. Genetic analysis of male and female fertility using longitudinal binary data. J. Dairy Sci. 87:3947-3952. https://doi.org/10.3168/jds.S0022-0302(04)73534 $-1$.

Baba, T., Y. Gotoh, S. Yamaguchi, S. Nakagawa, H. Abe, Y. Masuda, and T. Kawahara. 2017. Application of single-step genomic best linear unbiased prediction with a multiple-lactation random regression test-day model for Japanese Holsteins. Anim. Sci. J. 88:1226-1231. https://doi.org/10.1111/asj.12760.

Banos, G., and G. E. Shook. 1990. Genotype by environment interaction and genetic correlations among parities for somatic cell count and milk yield. J. Dairy Sci. 73:2563-2573. https://doi.org/10 $.3168 /$ jds.S0022-0302(90)78942-4.

Bartolomé, E., A. Menéndez-Buxadera, A. Molina, and M. Valera. 2018. Plasticity effect of rider-horse interaction on genetic evaluations for Show Jumping discipline in sport horses. J. Anim. Breed. Genet. 135:138-148. https://doi.org/10.1111/jbg.12315.

Bignardi, A. B., L. El Faro, R. A. A. Torres Júnior, V. L. Cardoso, P. F. Machado, and L. G. Albuquerque. 2011. Random regression models using different functions to model test-day milk yield of Brazilian Holstein cows. Genet. Mol. Res. 10:3565-3575. https:// doi.org/10.4238/2011.October.31.4.

Bionaz, M., and J. J. Loor. 2008. ACSL1, AGPAT6, FABP3, LPIN1, and $S L C 27 A 6$ are the most abundant isoforms in bovine mammary tissue and their expression is affected by stage of lactation. J. Nutr. 138:1019-1024. https://doi.org/10.1093/jn/138.6.1019.

Bohmanova, J., F. Miglior, J. Jamrozik, I. Misztal, and P. G. Sullivan. 2008. Comparison of random regression models with Legendre polynomials and linear Splines for production traits and somatic cell score of Canadian Holstein cows. J. Dairy Sci. 91:3627-3638. https://doi.org/10.3168/jds.2007-0945.

Boichard, D., V. Ducrocq, P. Croiseau, and S. Fritz. 2016. Genomic selection in domestic animals: Principles, applications and perspectives. C. R. Biol. 339:274-277. https://doi.org/10.1016/j.crvi 2016.04.007. 
Boligon, A. A., F. Baldi, M. E. Z. Mercadante, R. B. Lôbo, R. J. Pereira, and L. G. Albuquerque. 2011. Breeding value accuracy estimates for growth traits using random regression and multi-trait models in Nelore cattle. Genet. Mol. Res. 10:1227-1236. https:// doi.org/10.4238/vol10-2gmr1087.

Borquis, R. R. A., F. R. A. Neto, F. Baldi, N. Hurtado-Lugo, G. M. F. de Camargo, M. Muñoz-Berrocal, and H. Tonhati. 2013. Multipletrait random regression models for the estimation of genetic parameters for milk, fat, and protein yield in buffaloes. J. Dairy Sci. 96:5923-5932. https://doi.org/10.3168/jds.2012-6023.

Bouallegue, M., R. Steri, N. M'hamdi, and M. Ben Hamouda. 2015. Modelling of individual lactation curves of Tunisian Holstein-Friesian cows for milk yield, fat, and protein contents using parametric, orthogonal and spline models. J. Anim. Feed Sci. 24:11-18. https://doi.org/10.22358/jafs/65648/2015.

Brito, L. F., F. G. Silva, H. R. Oliveira, N. Souza, G. Caetano, E. V. Costa, G. R. O. Menezes, A. L. P. Melo, M. T. Rodrigues, and R. A. Torres. 2018. Modelling lactation curves of dairy goats by fitting random regression models using Legendre polynomials or B-splines. Can. J. Anim. Sci. 98:73-83. https://doi.org/10.1139/ CJAS-2017-0019.

Brody, S., and H. A. Lardy. 1946. Bioenergetics and growth. J. Phys. Chem. 50:168-169. https://doi.org/10.1021/j150446a008.

Brown, J. E., C. J. Brown, and W. T. Butts. 1972. A discussion of the genetic aspects of weight, mature weight and rate of maturing in Hereford and Angus cattle. J. Anim. Sci. 34:525-537. https://doi .org/10.2527/jas1972.344525x

Brügemann, K., E. Gernand, U. U. von Borstel, and S. König. 2013. Application of random regression models to infer the genetic background and phenotypic trajectory of binary conception rate by alterations of temperature $\times$ humidity indices. Livest. Sci. 157:389396. https://doi.org/10.1016/j.livsci.2013.08.009.

Buitenhuis, B., L. L. Janss, N. A. Poulsen, L. B. Larsen, M. K. Larsen, and P. Sørensen. 2014. Genome-wide association and biological pathway analysis for milk-fat composition in Danish Holstein and Danish Jersey cattle. BMC Genomics 15:1112. https://doi.org/10 .1186/1471-2164-15-1112.

Calus, M. P. L., and R. F. Veerkamp. 2003. Estimation of environmental sensitivity of genetic merit for milk production traits using a random regression model. J. Dairy Sci. 86:3756-3764. https://doi .org/10.3168/jds.S0022-0302(03)73982-4.

Campbell, M. T., H. Walia, and G. Morota. 2018. Utilizing random regression models for genomic prediction of a longitudinal trait derived from high-throughput phenotyping. Plant Direct 2. https: //doi.org/10.1002/pld3.80.

Campos, G. S., F. A. Reimann, L. L. Cardoso, C. E. R. Ferreira, V. S. Junqueira, P. I. Schmidt, J. Braccini Neto, M. J. I. Yokoo, B. P. Sollero, A. A. Boligon, and F. F. Cardoso. 2018. Genomic prediction using different estimation methodology, blending and cross-validation techniques for growth traits and visual scores in Hereford and Braford cattle. J. Anim. Sci. 96:2579-2595. https:// doi.org/10.1093/jas/sky175.

Carvalheira, J. G. V., R. W. Blake, E. J. Pollak, R. L. Quaas, and C. V. Duran-Castro. 1998. Application of an autoregressive process to estimate genetic parameters and breeding values for daily milk yield in a tropical herd of Lucerna cattle and in United States Holstein herds. J. Dairy Sci. 81:2738-2751. https://doi.org/10.3168/ jds.S0022-0302(98)75831-X

CDN. 2016. Improving existing traits and adding exciting new ones. Canadian Dairy Network. Accessed Oct. 2, 2018. https://www.cdn .ca/document.php?id=442.

Christensen, O. F., and M. S. Lund. 2010. Genomic relationship matrix when some animals are not genotyped genomic prediction models. Genet. Sel. Evol. 42:1-8.

Christensen, O. F., P. Madsen, B. Nielsen, T. Ostersen, and G. Su. 2012. Single-step methods for genomic evaluation in pigs. Animal 6:1565-1571. https://doi.org/10.1017/S1751731112000742.

Costa, R. B., I. Misztal, M. A. Elzo, J. K. Bertrand, L. O. C. Silva, and M. Eukaszewicz. 2011. Estimation of genetic parameters for mature weight in Angus cattle. J. Anim. Sci. 89:2680-2686. https: //doi.org/10.2527/jas.2010-3574.
Crispim, A. C., M. J. Kelly, S. E. F. Guimarães, F. F. Silva, M. R. S. Fortes, R. R. Wenceslau, and S. Moore. 2015. Multi-trait GWAS and new candidate genes annotation for growth curve parameters in Brahman cattle. PLoS One 10:e0139906. https://doi.org/10 .1371/journal.pone.0139906.

Danell, B. 1982. Studies on lactation yield and individual test-day yields of Swedish dairy cows. Acta Agric. Scand. 32:83-92. https: /doi.org/10.1080/00015128209435734.

Das, K., J. Li, Z. Wang, C. Tong, G. Fu, Y. Li, M. Xu, K. Ahn, D Mauger, R. Li, and R. Wu. 2011. A dynamic model for genomewide association studies. Hum. Genet. 129:629-639. https://doi .org/10.1007/s00439-011-0960-6.

David, I., L. Bodin, G. Lagriffoul, E. Manfredi, and C. Robert-Granié 2007. Character process model for semen volume in AI rams: Evaluation of correlation structures for long and short-term environmental effects. Genet. Sel. Evol. 39:55. https://doi.org/10.1051/ gse:2006033

de Boor, C. R. J. 1980. A practical guide to Splines. Math. Comput 34:325. https://doi.org/10.2307/2006241.

DeNise, R. S. K. and J. Brinks. 1985. Genetic and environmental aspects of the growth curve parameters in beef cows. J. Anim. Sci. 61:1431-1440.https://doi.org/10.2527/jas1985.6161431x.

Ferris, T. A., I. L. Mao, and C. R. Anderson. 1985. Selecting for lactation curve and milk yield in dairy cattle. J. Dairy Sci. 68:14381448. https://doi.org/10.3168/jds.S0022-0302(85)80981-4.

Flores, E. B., and J. van der Werf. 2015. Random regression test day models to estimate genetic parameters for milk yield and milk components in Philippine dairy buffaloes. J. Anim. Breed. Genet. 132:289-300. https://doi.org/10.1111/jbg.12133.

Forni, S., D. Gianola, G. J. M. Rosa, and G. de los Campos. 2009. A dynamic linear model for genetic analysis of longitudinal traits1. J. Anim. Sci. 87:3845-3853. https://doi.org/10.2527/jas.2008-1514.

Gao, H., M. S. Lund, Y. Zhang, and G. Su. 2013. Accuracy of genomic prediction using different models and response variables in the Nordic Red cattle population. J. Anim. Breed. Genet. 130:330340. https://doi.org/10.1111/jbg.12039.

García-Ruiz, A., J. B. Cole, P. M. VanRaden, G. R. Wiggans, F. J. Ruiz-López, and C. P. Van Tassell. 2016. Changes in genetic selection differentials and generation intervals in US Holstein dairy cattle as a result of genomic selection. Proc. Natl. Acad. Sci. USA 113:E3995-E4004. https://doi.org/10.1073/pnas.1519061113.

Garrick, D. J., J. F. Taylor, and R. L. Fernando. 2009. Deregressing estimated breeding values and weighting information for genomic regression analyses. Genet. Sel. Evol. 41:55. https://doi.org/10 $.1186 / 1297-9686-41-55$.

Ghiasi, H., and M. J. Carabaño. 2018. Eigenvector index for two female fertility traits based in random regression coefficients matrix in Holstein cows. Span. J. Agric. Res. 16:e0401. https://doi.org/10 $.5424 / \mathrm{sjar} / 2018161-12396$.

Ghouse, J., M. W. Skov, R. S. Bigseth, G. Ahlberg, J. K. Kanters, and M. S. Olesen. 2018. Distinguishing pathogenic mutations from background genetic noise in cardiology: The use of large genome databases for genetic interpretation. Clin. Genet. 93:459-466. https://doi.org/10.1111/cge.13066.

Goddard, M. E., B. J. Hayes, and T. H. E. Meuwissen. 2010. Genomic selection in livestock populations. Genet. Res. (Camb.) 92:413421. https://doi.org/10.1017/S0016672310000613.

Gompertz, B. 1825. On the nature of the function expressive of the law of human mortality, and on a new mode of determining the value of life contingencies. Philos. Trans. R. Soc. Lond. 115:513-583. https://doi.org/10.1098/rstl.1825.0026.

González-Peña, D., J. Acosta, D. Guerra, N. González, M. Acosta, D. Sosa, and G. Torres-Hernández. 2012. Modeling of individual lactation curves for milk production in a population of Alpine goats in Cuba. Livest. Sci. 150:42-50. https://doi.org/10.1016/j .livsci.2012.07.026.

Guo, Z., G. Liu, M. S. Röder, J. C. Reif, M. W. Ganal, and T. Schnurbusch. 2018. Genome-wide association analyses of plant growth traits during the stem elongation phase in wheat. Plant Biotechnol. J. 16:2042-2052. https://doi.org/10.1111/pbi.12937. 
Gyawali, S., S. Chao, S. S. Vaish, S. P. Singh, S. Rehman, S. R. Vishwakarma, and R. P. S. Verma. 2018. Genome wide association studies (GWAS) of spot blotch resistance at the seedling and the adult plant stages in a collection of spring barley. Mol. Breed. 38:1-14. https://doi.org/10.1007/s11032-018-0815-0.

Harris, B. L., and D. L. Johnson. 2010. Genomic predictions for New Zealand dairy bulls and integration with national genetic evaluation. J. Dairy Sci. 93:1243-1252. https://doi.org/10.3168/jds.2009 -2619 .

Harville, D. A. 1979. Recursive estimation using mixed linear models with autoregressive random effects. Pages $1-10$ in Proc. Conf. in Honor of C. R. Henderson, Cornell University, Ithaca, NY. Cornell University Press, Ithaca, NY.

Hayes, B., and M. Goddard. 2010. Genome-wide association and genomic selection in animal breeding. Genome 53:876-883. https:// doi.org/10.1139/G10-076.

Henderson, C. R. 1963. Selection index and expected genetic advance. Stat. Genet. Plant Breed. 892:141-163.

Henderson, C. R. 1973. Sire evaluation and genetic trends. J. Anim. Sci. 1973:10-41. https://doi.org/10.1093/ansci/1973.Symposium 10 .

Henderson, C. R. Jr. 1982. Analysis of covariance in the mixed model: Higher-level, nonhomogeneous, and random regressions. Biometrics 38:623. https://doi.org/10.2307/2530044.

Higgins, M. G., C. Fitzsimons, M. C. McClure, C. McKenna, S. Conroy, D. A. Kenny, M. McGee, S. M. Waters, and D. W. Morris. 2018. GWAS and eQTL analysis identifies a SNP associated with both residual feed intake and GFRA2 expression in beef cattle. Sci. Rep. 8:14301.

Howard, J. T., S. Jiao, F. Tiezzi, Y. Huang, K. A. Gray, and C. Maltecca. 2015. Genome-wide association study on Legendre random regression coefficients for the growth and feed intake trajectory on Duroc boars. BMC Genet. 16:59. https://doi.org/10.1186/ s12863-015-0218-8.

Huynh-Tran, V. H., H. Gilbert, and I. David. 2017. Genetic structured antedependence and random regression models applied to the longitudinal feed conversion ratio in growing Large White pigs. J. Anim. Sci. 95:4752-4763. https://doi.org/10.2527/jas2017.1864.

Interbull. 2017a. Description of national genomic evaluation systems. Canada. Accessed May 2, 2018. http://www.interbull.org/ib/ nationalgenoforms.

Interbull. 2017b. Interbull CoP: Methods of international evaluation. Accessed Mar. 17, 2019. http://www.interbull.org/ib/cop_chap5.

Interbull. 2018. Description of national genetic evaluation systems. Accessed May 2, 2018. http://www.interbull.org/ib/geforms.

Iwaisaki, H., S. Tsuruta, I. Misztal, and J. K. Bertrand. 2005. Genetic parameters estimated with multitrait and linear spline-random regression models using Gelbvieh early growth data. J. Anim. Sci. 83:757-763. https://doi.org/10.2527/2005.834757x.

Jaffrézic, F., E. Venot, D. Laloë, A. Vinet, and G. Renand. 2004. Use of structured antedependence models for the genetic analysis of growth curves. J. Anim. Sci. 82:3465-3473. https://doi.org/10 $.2527 / 2004.82123465 x$.

Jamrozik, J., J. Bohmanova, and L. R. Schaeffer. 2010. Selection of locations of knots for linear splines in random regression test-day models. J. Anim. Breed. Genet. 127:87-92. https://doi.org/10 .1111/j.1439-0388.2009.00829.x.

Jamrozik, J., D. Gianola, and L. R. Schaeffer. 2001. Bayesian estimation of genetic parameters for test day records in dairy cattle using linear hierarchical models. Livest. Prod. Sci. 71:223-240. https:// doi.org/10.1016/S0301-6226(01)00186-5.

Jamrozik, J., G. Jansen, L. R. Schaeffer, and Z. Liu. 1998a. Analysis of persistency of lactation calculated from a random regression test day model. Interbull Bull. 17:64-69.

Jamrozik, J., G. J. Kistemaker, J. C. M. Dekkers, and L. R. Schaeffer. 1997a. Comparison of possible covariates for use in a random regression model for analyses of test day yields. J. Dairy Sci. https: //doi.org/10.3168/jds.S0022-0302(97)76210-6.

Jamrozik, J., and L. R. Schaeffer. 1997. Estimates of genetic parameters for a test day model with random regressions for yield traits of first lactation Holsteins. J. Dairy Sci. https://doi.org/10.3168/ jds.S0022-0302(97)75996-4.

Jamrozik, J., and L. R. Schaeffer. 2002. Bayesian comparison of random regression models for test-day yields in dairy cattle. Pages 21-24 in Proc. 7th World Congr. Genet. Appl. Livest. Prod., Montpellier, France. Editions Quae, Versailles, France.

Jamrozik, J., L. R. Schaeffer, and J. C. Dekkers. 1997b. Genetic evaluation of dairy cattle using test day yields and random regression model. J. Dairy Sci. https://doi.org/10.3168/jds.S0022 -0302(97)76050-8.

Jamrozik, J., L. R. Schaeffer, and F. Grignola. 1998b. Genetic parameters for production traits and somatic cell score of Canadian Holsteins with multiple trait random regression model. Page 3 in Proc. 6th World Congr. Genet. Appl. Livest. Prod., Armidale, Australia. University of New England, Armidale, NSW, Australia.

Jamrozik, J., L. R. Schaeffer, Z. Liu, and G. Jansen. 1997c. Multiple trait random regression test day model for production traits. Interbull Bull. 43:43-47

Jattawa, D., M. A. Elzo, S. Koonawootrittriron, and T. Suwanasopee. 2016. Genomic-polygenic and polygenic evaluations for milk yield and fat percentage using random regression models with Legendre polynomials in a Thai multibreed dairy population. Livest. Sci. 188:133-141. https://doi.org/10.1016/j.livsci.2016.04.019.

Jenko, J., G. R. Wiggans, T. A. Cooper, S. A. E. Eaglen, W. G. L. Luff, M. Bichard, R. Pong-Wong, and J. A. Woolliams. 2017. Cow genotyping strategies for genomic selection in a small dairy cattle population. J. Dairy Sci. 100:439-452. https://doi.org/10.3168/jds .2016-11479.

Jensen, J. 2001. Genetic evaluation of dairy cattle using test-day models. J. Dairy Sci. 84:2803-2812. https://doi.org/10.3168/jds.S0022 -0302(01)74736-4.

Kang, H., C. Ning, L. Zhou, S. Zhang, Q. Yan, and J. F. Liu. 2018. Short communication: Single-step genomic evaluation of milk production traits using multiple-trait random regression model in Chinese Holsteins. J. Dairy Sci. 101:11143-11149. https://doi.org/ 10.3168/jds.2018-15090.

Kang, H., L. Zhou, R. Mrode, Q. Zhang, and J. F. Liu. 2017. Incorporating the single-step strategy into a random regression model to enhance genomic prediction of longitudinal traits. Heredity 119:459-467. https://doi.org/10.1038/hdy.2016.91.

Kennedy, B. W., and C. R. Henderson. 1975. Components of variance of growth traits among Hereford and Aberdeen Angus calves. Can. J. Anim. Sci. 55:493-502. https://doi.org/10.4141/cjas75-061.

Khanzadeh, H., N. Ghavi Hossein-Zadeh, M. Naserani, and B. Mohammad Nazari. 2013. Calculating daughter yield deviations for production traits in Holstein cattle using repeatability animal and random regression test day models. Livest. Sci. 157:408-413. https: //doi.org/10.1016/j.livsci.2013.08.018.

Kheirabadi, K. 2018. Bayesian analysis of random regression models to model test-day somatic cell score of primiparous Holstein cattle in Iran. J. Appl. Anim. Res. 46:677-684. https://doi.org/10.1080/ 09712119.2017.1386107.

Kirkpatrick, M., D. Lofsvold, and M. Bulmer. 1990. Analysis of the inheritance, selection and evolution of growth trajectories. Genetics 124:979-993.

Kistemaker, G. J. 1997. The comparison of random regression test day models and a 305-day for evaluation of milk yield in dairy cattle. $\mathrm{PhD}$ Thesis. University of Guelph, Guelph, ON, Canada.

Koivula, M., I. Strandén, J. Pösö, G. P. Aamand, and E. A. Mäntysaari. 2015. Single-step genomic evaluation using multitrait random regression model and test-day data. J. Dairy Sci. 98:2775-2784. https://doi.org/10.3168/jds.2014-8975.

Koivula, M., I. Strandén, G. Su, and E. A. Mäntysaari. 2012. Different methods to calculate genomic predictions - Comparisons of BLUP at the single nucleotide polymorphism level (SNP-BLUP), BLUP at the individual level (G-BLUP), and the one-step approach $(\mathrm{H}-$ BLUP). J. Dairy Sci. 95:4065-4073. https://doi.org/10.3168/jds .2011-4874.

König, S., H. Simianer, and A. Willam. 2009. Economic evaluation of genomic breeding programs. J. Dairy Sci. 92:382-391. https://doi .org/10.3168/jds.2008-1310. 
Laird, N. M., and J. H. Ware. 1982. Random-effects models for longitudinal data. Biometrics 38:963. https://doi.org/10.2307/2529876.

Lamb, R. C., and L. D. McGilliard. 1967. Ratio factors to estimate 305-day production from lactation records in progress. J. Dairy Sci. 50:1101-1108. https://doi.org/10.3168/jds.S0022-0302(67)87573 -8 .

Lázaro, S. F., N. Ibáñez-Escriche, L. Varona, F. F. Silva, L. C. Brito, S. E. F. Guimarães, and P. S. Lopes. 2017. Bayesian analysis of pig growth curves combining pedigree and genomic information. Livest. Sci. 201:34-40. https://doi.org/10.1016/j.livsci.2017.03.024.

Legarra, A., O. F. Christensen, I. Aguilar, and I. Misztal. 2014. Single step, a general approach for genomic selection. Livest. Sci. 166:5465. https://doi.org/10.1016/j.livsci.2014.04.029.

Lennon, H. D., and J. P. Mixner. 1958. Relation of lactation milk production in dairy cows to maximum initial milk yield and persistency of lactation. J. Dairy Sci. 41:969-976.

León, J. M., N. P. P. Macciotta, L. T. Gama, C. Barba, and J. V. Delgado. 2012. Characterization of the lactation curve in MurcianoGranadina dairy goats. Small Rumin. Res. 107:76-84. https://doi .org/10.1016/j.smallrumres.2012.05.012.

Lidauer, M., E. A. Mäntysaari, and I. Strandén. 2003. Comparison of test-day models for genetic evaluation of production traits in dairy cattle. Livest. Prod. Sci. 79:73-86. https://doi.org/10.1016/S0301 $-6226(02) 00142-2$.

Lillehammer, M., J. Ødegård, and T. H. Meuwissen. 2007. Random regression models for detection of gene by environment interaction. Genet. Sel. Evol. 39:105. https://doi.org/10.1051/gse:2006037.

Lindgren, N., J. Philipsson, and A. Elofson-Bernstedt. 1980. Studies on monthly protein records of individual cows. Acta Agric. Scand. 30:437-444. https://doi.org/10.1080/00015128009435291.

Lourenco, D. A. L., I. Misztal, S. Tsuruta, I. Aguilar, E. Ezra, M. Ron, A. Shirak, and J. I. Weller. 2014a. Methods for genomic evaluation of a relatively small genotyped dairy population and effect of genotyped cow information in multiparity analyses. J. Dairy Sci. 97:1742-1752. https://doi.org/10.3168/jds.2013-6916.

Lourenco, D. A. L., I. Misztal, S. Tsuruta, I. Aguilar, T. J. Lawlor, S. Forni, and J. I. Weller. 2014b. Are evaluations on young genotyped animals benefiting from the past generations? J. Dairy Sci. 97:3930-3942. https://doi.org/10.3168/jds.2013-7769.

Lu, D., S. Miller, M. Sargolzaei, M. Kelly, G. Vander Voort, T. Caldwell, Z. Wang, G. Plastow, and S. Moore. 2013. Genome-wide association analyses for growth and feed efficiency traits in beef cattle. J. Anim. Sci. 91:3612-3633. https://doi.org/10.2527/jas $.2012-5716$

Lund, M. S., P. Sorensen, P. Madsen, and F. Jaffrézic. 2008. Detection and modelling of time-dependent QTL in animal populations. Genet. Sel. Evol. 40:177-194. https://doi.org/10.1051/gse: 2007043

Macciotta, N. P. P., G. Gaspa, L. Bomba, D. Vicario, C. Dimauro, M Cellesi, and P. Ajmone-Marsan. 2015. Genome-wide association analysis in Italian Simmental cows for lactation curve traits using a low-density (7K) SNP panel. J. Dairy Sci. 98:8175-8185. https:/ /doi.org/10.3168/jds.2015-9500.

Makgahlela, M. L., T. Knürr, G. P. Aamand, I. Strandén, and E. A. Mäntysaari. 2013. Single step evaluations using haplotype segments. Interbull Bull. 47:23-25.

Mäntysaari, E. A., M. Koivula, I. Strandén, J. Pösö, G. P. Aamand, and F. Coop. 2011. Estimation of GEBVs using deregressed individual cow breeding values. Interbull Bull. 44:19-24.

Martínez, R., D. Bejarano, Y. Gómez, R. Dasoneville, A. Jiménez, G. Even, J. Sölkner, and G. Mészáros. 2017. Genome-wide association study for birth, weaning and yearling weight in Colombian Brahman cattle. Genet. Mol. Biol. 40:453-459. https://doi.org/10 .1590/1678-4685-GMB-2016-0017.

Masuda, Y., I. Misztal, S. Tsuruta, A. Legarra, I. Aguilar, D. A. L. Lourenco, B. O. Fragomeni, and T. J. Lawlor. 2016. Implementation of genomic recursions in single-step genomic best linear unbiased predictor for US Holsteins with a large number of genotyped animals. J. Dairy Sci. 99:1968-1974. https://doi.org/10.3168/jds $.2015-10540$
Masuda, Y., P. M. VanRaden, I. Misztal, and T. J. Lawlor. 2018. Differing genetic trend estimates from traditional and genomic evaluations of genotyped animals as evidence of preselection bias in US Holsteins. J. Dairy Sci. 101:5194-5206. https://doi.org/10.3168/ jds.2017-13310.

Meng, Q., K. Wang, X. Liu, H. Zhou, L. Xu, Z. Wang, and M. Fang. 2017. Identification of growth trait related genes in a Yorkshire purebred pig population by genome-wide association studies. Asian-Australas. J. Anim. Sci. 30:462-469. https://doi.org/10 .5713 /ajas.16.0548.

Meuwissen, T., B. Hayes, and M. Goddard. 2016. Genomic selection: A paradigm shift in animal breeding. Anim. Front. 6:6-14. https:/ /doi.org/10.2527/af.2016-0002.

Meuwissen, T. H. E., B. J. Hayes, and M. E. Goddard. 2001. Prediction of total genetic value using genome-wide dense marker maps. Genetics 157:1819-1820.

Meyer, B. K. 1999. Estimates of genetic and phenotypic covariance functions for postweaning growth and mature weight of beef cows. J. Anim. Breed. Genet. 116:181-205. https://doi.org/10.1046/j .1439-0388.1999.00193.x.

Meyer, K. 1995. Estimates of genetic parameters for mature weight of Australian beef cows and its relationship to early growth and skeletal measures. Livest. Prod. Sci. 44:125-137. https://doi.org/ 10.1016/0301-6226(95)00067-4.

Meyer, K. 2005. Random regression analyses using B-splines to model growth of Australian Angus cattle. Genet. Sel. Evol. 37:473-500. https://doi.org/10.1051/gse:2005012.

Meyer, K., H. U. Graser, and K. Hammond. 1989. Estimates of genetic parameters for first-lactation test-day production of Australian black and white cows. Livest. Prod. Sci. 21:177-199. https://doi .org/10.1016/0301-6226(89)90049-3.

Meyer, K., and W. G. Hill. 1997. Estimation of genetic and phenotypic covariance functions for longitudinal or 'repeated' records by restricted maximum likelihood. Livest. Prod. Sci. 47:185-200. https: //doi.org/10.1016/S0301-6226(96)01414-5.

Misztal, I. 2006. Properties of random regression models using linear splines. J. Anim. Breed. Genet. 123:74-80. https://doi.org/10 .1111/j.1439-0388.2006.00582.x.

Misztal, I., H. L. Bradford, D. A. L. Lourenco, S. Tsuruta, Y. Masuda, A. Legarra, and T. J. Lawlor. 2017. Studies on inflation of GEBV in single-step GBLUP for type. Interbull Bull. 51:38-42.

Misztal, I., B. O. Fragomeni, D. A. L. Lourenco, S. Tsuruta, Y. Masuda, I. Aguilar, A. Legarra, and T. Lawlor. 2015. Efficient inversion of genomic relationship matrix by the algorithm for proven and young (APY). Int. Bull. 49:111-116.

Misztal, I., A. Legarra, and I. Aguilar. 2009. Computing procedures for genetic evaluation including phenotypic, full pedigree, and genomic information. J. Dairy Sci. 92:4648-4655. https://doi.org/10 $.3168 /$ jds.2009-2064

Misztal, I., A. Legarra, and I. Aguilar. 2014. Using recursion to compute the inverse of the genomic relationship matrix. J. Dairy Sci 97:3943-3952. https://doi.org/10.3168/jds.2013-7752.

Misztal, I., T. Strabel, J. Jamrozik, E. A. Mäntysaari, and T. H. E. Meuwissen. 2000. Strategies for estimating the parameters needed for different test-day models. J. Dairy Sci. 83:1125-1134. https:// doi.org/10.3168/jds.S0022-0302(00)74978-2.

Miyumo, S., C. B. Wasike, and A. K. Kahi. 2018. Genetic and phenotypic parameters for feed efficiency in indigenous chicken in $\mathrm{Ke}-$ nya. Livest. Sci. 207:91-97. https://doi.org/10.1016/j.livsci.2017 .11 .011 .

Morant, S. V., and A. Gnanasakthy. 1989. A new approach to the mathematical formulation of lactation curves. Anim. Prod. 49:151-162. https://doi.org/10.1017/S000335610003227X.

Mota, L. F. M., P. G. M. A. Martins, T. O. Littiere, L. R. A. Abreu, M. A. Silva, and C. M. Bonafé. 2018a. Genetic evaluation and selection response for growth in meat-type quail through random regression models using B-spline functions and Legendre polynomials. Animal 12:667-674. https://doi.org/10.1017/S1751731117001951.

Mota, R. R., P. S. Lopes, R. J. Tempelman, F. F. Silva, I. Aguilar, C C. G. Gomes, and F. F. Cardoso. 2016. Genome-enabled prediction for tick resistance in Hereford and Braford beef cattle via re- 
action norm models. J. Anim. Sci. 94:1834-1843. https://doi.org/ 10.2527/jas.2015-0194.

Mota, R. R., F. F. Silva, P. S. Lopes, R. J. Tempelman, B. P. Sollero, I. Aguilar, and F. F. Cardoso. 2018b. Analyses of reaction norms reveal new chromosome regions associated with tick resistance in cattle. Animal 12:205-214. https://doi.org/10.1017/ S1751731117001562.

Nayeri, S., M. Sargolzaei, M. K. Abo-Ismail, N. May, S. P. Miller, F. Schenkel, S. S. Moore, and P. Stothard. 2016. Genome-wide association for milk production and female fertility traits in Canadian dairy Holstein cattle. BMC Genet. 17:75. https://doi.org/10.1186/ s12863-016-0386-1.

Nejati-Javaremi, A., C. Smith, and J. P. Gibson. 1997. Effect of total allelic relationship on accuracy of evaluation and response to selection. J. Anim. Sci. 75:1738. https://doi.org/10.2527/1997 $.7571738 x$.

Ning, C., H. Kang, L. Zhou, D. Wang, H. Wang, A. Wang, J. Fu, S. Zhang, and J. Liu. 2017. Performance gains in genome-wide association studies for longitudinal traits via modeling time-varied effects. Sci. Rep. 7:590. https://doi.org/10.1038/s41598-017-00638 $-2$

Ning, C., D. Wang, X. Zheng, Q. Zhang, S. Zhang, R. Mrode, and J.F. Liu. 2018. Eigen decomposition expedites longitudinal genomewide association studies for milk production traits in Chinese Holstein. Genet. Sel. Evol. 50:12. https://doi.org/10.1186/s12711-018 $-0383-0$.

Norman, H. D., F. N. Dickinson, and J. R. Wright. 1985. Merit of extending completed records of less than 305 days. J. Dairy Sci. 68:2646-2654. https://doi.org/10.3168/jds.S0022-0302(85)81149 -8 .

Nustad, H. E., C. M. Page, A. H. Reiner, M. Zucknick, and M. LeBlanc. 2018. A Bayesian mixed modeling approach for estimating heritability. BMC Proc. 12:31. https://doi.org/10.1186/s12919-018 $-0131-z$

Oliveira, D. P., D. A. L. Lourenco, S. Tsuruta, I. Misztal, D. J. A. Santos, F. R. de Araújo Neto, R. R. Aspilcueta-Borquis, F. Baldi, R. Carvalheiro, G. M. F. de Camargo, L. G. Albuquerque, and H. Tonhati. 2018a. Reaction norm for yearling weight in beef cattle using single-step genomic evaluation1. J. Anim. Sci. 96:27-34. https://doi.org/10.1093/jas/skx006.

Oliveira, H. R., L. F. Brito, M. Sargolzaei, F. F. Silva, J. Jamrozik, D. A. L. Lourenco, and F. S. Schenkel. 2019c. Impact of including information from bulls and their daughters in the training population of multiple-step genomic evaluations in dairy cattle: A simulation study. J. Anim. Breed. Genet. 137:1-12. https://doi .org/10.1111/jbg.12407.

Oliveira, H. R., L. F. Brito, F. F. Silva, D. A. L. Lourenco, J. Jamrozik, and F. S. Schenkel. 2019b. Genomic prediction of lactation curves for milk, fat, protein and somatic cell score in Holstein cattle. J. Dairy Sci. 102:452-463. https://doi.org/10.3168/jds.2018 $-15159$

Oliveira, H. R., D. A. L. Lourenco, Y. Masuda, I. Misztal, S. Tsuruta, J. Jamrozik, L. F. Brito, F. F. Silva, and F. S. Schenkel. 2019a. Application of single-step genomic evaluation using multiple-trait random regression test-day models in dairy cattle. J. Dairy Sci. 102:2365-2377. https://doi.org/10.3168/jds.2018-15466.

Oliveira, H. R., F. F. Silva, L. F. Brito, A. R. Guarini, J. Jamrozik, and F. S. Schenkel. 2018b. Comparing deregression methods for genomic prediction of test-day traits in dairy cattle. J. Anim. Breed. Genet. 135:97-106. https://doi.org/10.1111/jbg.12317.

Oliveira, H. R., F. F. Silva, M. V. G. B. Silva, O. H. G. B. D. Siqueira, M. A. Machado, J. C. C. Panetto, L. S. Glória, and L. F. Brito. 2017a. Bayesian models combining Legendre and B-spline polynomials for genetic analysis of multiple lactations in Gyr cattle. Livest. Sci. 201:78-84. https://doi.org/10.1016/j.livsci.2017.05.007.

Oliveira, H. R., F. F. Silva, O. H. G. B. D. Siqueira, N. O. Souza, V. S. Junqueira, M. D. V. Resende, R. R. A. Borquis, and M. T. Rodrigues. 2016. Combining different functions to describe milk, fat, and protein yield in goats using Bayesian multiple-trait random regression models. J. Anim. Sci. 94:1865-1874. https://doi.org/10 $.2527 /$ jas.2015-0150.
Oliveira, L. T., C. M. Bonafé, F. F. Silva, H. T. Ventura, H. R. Oliveira, G. R. O. Menezes, M. D. V. Resende, and J. M. S. Viana. 2017b. Bayesian random regression threshold models for genetic evaluation of pregnancy probability in Red Sindhi heifers. Livest. Sci. 202:166-170. https://doi.org/10.1016/j.livsci.2017.06.005.

Padilha, A. H., E. P. M. Alfonzo, D. S. Daltro, H. A. L. Torres, J. B. Neto, and J. A. Cobuci. 2018. Genetic trends and genetic correlations between 305-day milk yield, persistency and somatic cell score of Holstein cows in Brazil using random regression model. Anim. Prod. Sci. https://doi.org/10.1071/AN16835.

Pander, B., and W. Hill. 1993. Genetic evaluation of lactation yield from test day records on incomplete lactation. Livest. Prod. Sci. 37:23-36. https://doi.org/10.1016/0301-6226(93)90062-M.

Patry, C., and V. Ducrocq. 2011. Accounting for genomic preselection in national BLUP evaluations in dairy cattle. Genet. Sel. Evol. 43:30. https://doi.org/10.1186/1297-9686-43-30.

Pereira, R. J., A. B. Bignardi, L. El Faro, R. S. Verneque, A. E. Vercesi Filho, and L. G. Albuquerque. 2013. Random regression models using Legendre polynomials or linear splines for test-day milk yield of dairy Gyr (Bos indicus) cattle. J. Dairy Sci. 96:565-574. https: //doi.org/10.3168/jds.2011-5051.

Pletcher, S. D., and C. J. Geyer. 1999. The genetic analysis of agedependent traits: Modeling the character process. Genetics. https: //doi.org/10.1534/genetics.104.029181.

Powell, R. L., and H. D. Norman. 2006. Major advances in genetic evaluation techniques. J. Dairy Sci. 89:1337-1348. https://doi.org/ 10.3168/jds.S0022-0302(06)72201-9.

Pryce, J. E., S. Bolormaa, A. J. Chamberlain, P. J. Bowman, K. Savin, M. E. Goddard, and B. J. Hayes. 2010. A validated genome-wide association study in 2 dairy cattle breeds for milk production and fertility traits using variable length haplotypes. J. Dairy Sci. 93:3331-3345. https://doi.org/10.3168/jds.2009-2893.

Ptak, E., and L. R. Schaeffer. 1993. Use of test day yields for genetic evaluation of dairy sires and cows. Livest. Prod. Sci. 34:23-34. https://doi.org/10.1016/0301-6226(93)90033-E

Qiao, R., J. Gao, Z. Zhang, L. Li, X. Xie, Y. Fan, L. Cui, J. Ma, H. Ai, J. Ren, and L. Huang. 2015. Genome-wide association analyses reveal significant loci and strong candidate genes for growth and fatness traits in two pig populations. Genet. Sel. Evol. 47:17. https: //doi.org/10.1186/s12711-015-0089-5.

Quaas, R. L., R. D. Anderson, and A. R. Gilmour. 1984. Use of mixed models for prediction and for estimation of (co)variance components. Animal Genetics and Breeding Unit, University of New England, NSW, Australia.

Richards, F. J. 1959. A flexible growth function for empirical use. J. Exp. Bot. 10:290-301. https://doi.org/10.1093/jxb/10.2.290.

Rodriguez-Zas, S. L., B. R. Southey, D. W. Heyen, and H. A. Lewin. 2002. Detection of quantitative trait loci influencing dairy traits using a model for longitudinal data. J. Dairy Sci. 85:2681-2691. https://doi.org/10.3168/jds.S0022-0302(02)74354-3.

Rothschild, M. F., and C. R. Henderson. 1979. Maximum likelihood estimates of parameters of first and second lactation milk records. J. Dairy Sci. 62:990-995. https://doi.org/10.3168/jds.S0022 -0302(79)83360-3

Saghi, D. A., A. R. Shahdadi, F. K. Borzelabad, and K. Mohammadi. 2018. Estimates of covariance functions for growth of Kordi sheep in Iran using random regression models. Small Rumin. Res. 162:69-76. https://doi.org/10.1016/j.smallrumres.2018.03.007.

Samorè, A. B., and L. Fontanesi. 2016. Genomic selection in pigs: State of the art and perspectives. Ital. J. Anim. Sci. 15:211-232. https://doi.org/10.1080/1828051X.2016.1172034.

Sanchez, M. P., M. El Jabri, S. Minéry, V. Wolf, E. Beuvier, C. Laithier, A. Delacroix-Buchet, M. Brochard, and D. Boichard. 2018. Genetic parameters for cheese-making properties and milk composition predicted from mid-infrared spectra in a large data set of Montbéliarde cows. J. Dairy Sci. https://doi.org/10.3168/jds .2018-14878.

Santana, M. L. Jr., J. P. Eler, A. B. Bignardi, A. A. Boligon, and J. B. S. Ferraz. 2018. Genetic correlation between growth and reproductive performance of beef females depends on environment. Anim. Prod. Sci. 58:1201. https://doi.org/10.1071/AN16108. 
Santana, M. L., J. P. Eler, A. B. Bignardi, and J. B. S. Ferraz. 2015. Two-trait random regression model to estimate the genetic association of scrotal circumference with female reproductive performance in Nelore cattle. Theriogenology 83:1534-1540. https://doi .org/10.1016/j.theriogenology.2015.02.003.

Sawalha, R. M., J. F. Keown, S. D. Kachman, and L. D. Van Vleck. 2005. Evaluation of autoregressive covariance structures for testday records of Holstein cows: estimates of parameters. J. Dairy Sci. 88:2632-2642. https://doi.org/10.3168/jds.S0022-0302(05)72940 -4 .

Schaeffer, L. R. 2004. Application of random regression models in animal breeding. Livest. Prod. Sci. 86:35-45. https://doi.org/10 .1016/S0301-6226(03)00151-9.

Schaeffer, L. R. 2006. Strategy for applying genome-wide selection in dairy cattle. J. Anim. Breed. Genet. 123:218-223. https://doi.org/ 10.1111/j.1439-0388.2006.00595.x.

Schaeffer, L. R. 2016. Random regression models. Univ. of Guelph, Guelph, Ontario, Canada. Accessed: Nov. 10, 2018. http:// animalbiosciences.uoguelph.ca/ lrs/BOOKS/rrmbook.pdf.

Schaeffer, L. R. 2018. Necessary changes to improve animal models. J. Anim. Breed. Genet. https://doi.org/10.1111/jbg.12321.

Schaeffer, L. R., and J. C. Dekkers. 1994. Random regressions in animal models for test-day production in dairy cattle. Pages 443-446 in Proc. 5th World Congr. Genet. Appl. Livest. Prod., Guelph, ON, Canada. University of Guelph, Guelph, ON, Canada.

Schaeffer, L. R., J. Jamrozik, G. J. Kistemaker, and J. Van Doormaal. 2000. Experience with a test-day model. J. Dairy Sci. 83:11351144. https://doi.org/10.3168/jds.S0022-0302(00)74979-4.

Schaeffer, L. R., and J. W. Wilton. 1981. Estimation of variances and covariances for use in a multiple trait beef sire evaluation model Can. J. Anim. Sci. 61:531-538.

Shanks, R. D., P. J. Berger, A. E. Freeman, and F. N. Dickinson. 1981. Genetic aspects of lactation curves. J. Dairy Sci. 64:1852-1860. https://doi.org/10.3168/jds.S0022-0302(81)82775-0.

Silva, F. F., H. A. Mulder, E. F. Knol, M. S. Lopes, S. E. F. Guimarães, P. S. Lopes, P. K. Mathur, J. M. S. Viana, and J. W. M. Bastiaansen. 2014. Sire evaluation for total number born in pigs using a genomic reaction norms approach1. J. Anim. Sci. 92:38253834. https://doi.org/10.2527/jas.2013-6486.

Snelling, W. M., M. F. Allan, J. W. Keele, L. A. Kuehn, T. McDaneld, T. P. L. Smith, T. S. Sonstegard, R. M. Thallman, and G. L. Bennett. 2010. Genome-wide association study of growth in crossbred beef cattle. J. Anim. Sci. 88:837-848. https://doi.org/10.2527/jas .2009-2257.

Soares, A. C. C., S. E. F. Guimarães, M. J. Kelly, M. R. S. Fortes, F F. Silva, L. L. Verardo, R. Mota, and S. Moore. 2017. Multipletrait genomewide mapping and gene network analysis for scrotal circumference growth curves in Brahman cattle. J. Anim. Sci. 95:3331-3345. https://doi.org/10.2527/jas.2017.1409.

Speidel, S. E., R. M. Enns, and D. H. Crews Jr.. 2010. Genetic analysis of longitudinal data in beef cattle: A review. Genet. Mol. Res. 9:19-33. https://doi.org/10.4238/vol9-1gmr675.

Strabel, T., J. Szyda, E. Ptak, and J. Jamrozik. 2005. Comparison of random regression test-day models for Polish black and white cattle. J. Dairy Sci. 88:3688-3699. https://doi.org/10.3168/jds.S0022 $-0302(05) 73055-1$.

Strandberg, E., and B. Danell. 1989. Genetic and phenotypic parameters for production and days open in the first three lactations of Swedish dairy cattle. Acta Agric. Scand. 39:203-215. https://doi .org/10.1080/00015128909438513.

Strandén, I., and M. Lidauer. 1999. Solving large mixed linear models using preconditioned conjugate gradient iteration. J. Dairy Sci. 82:2779-2787. https://doi.org/10.3168/jds.S0022-0302(99)75535 $-9$.

Strucken, E. M., R. H. Bortfeldt, D. J. Koning, and G. A. Brockmann. 2012. Genome-wide associations for investigating time-dependent genetic effects for milk production traits in dairy cattle. Anim. Genet. 43:375-382. https://doi.org/10.1111/j.1365-2052.2011 .02278.x

Strucken, E. M., D. J. Koning, S. A. Rahmatalla, and G. A. Brockmann. 2011. Lactation curve models for estimating gene effects over a timeline. J. Dairy Sci. 94:442-449. https://doi.org/10.3168/ jds.2009-2932.

Strucken, E. M., Y. C. S. M. Laurenson, and G. A. Brockmann. 2015. Go with the flow-biology and genetics of the lactation cycle. Front. Genet. 6:118. https://doi.org/10.3389/fgene.2015.00118.

Suchocki, T., J. Szyda, and Q. Zhang. 2013. Modelling QTL effect on BTA06 using random regression test day models. J. Appl. Genet. 54:49-60. https://doi.org/10.1007/s13353-012-0114-0.

Swalve, H. H. 1995. The effect of test day models on the estimation of genetic parameters and breeding values for dairy yield traits. J. Dairy Sci. 78:929-938. https://doi.org/10.3168/jds.S0022 -0302(95)76708-X.

Swalve, H. H. 2000. Theoretical basis and computational methods for different test-day genetic evaluation methods. J. Dairy Sci 83:1115-1124. https://doi.org/10.3168/jds.S0022-0302(00)74977 $-0$.

Szyda, J., J. Komisarek, and I. Antkowiak. 2014. Modelling effects of candidate genes on complex traits as variables over time. Anim. Genet. 45:322-328. https://doi.org/10.1111/age.12144.

Tetens, J., G. Thaller, and N. Krattenmacher. 2014. Genetic and genomic dissection of dry matter intake at different lactation stages in primiparous Holstein cows. J. Dairy Sci. 97:520-531. https://doi .org/10.3168/jds.2013-7301.

Thepparat, M., W. Boonkum, M. Duangjinda, S. Tumwasorn, S. Nakavisut, and T. Thongchumroon. 2015. Genetic evaluation using random regression models with different covariance functions for test-day milk yield in an admixture population of Thailand goats. Anim. Sci. J. 86:655-660. https://doi.org/10.1111/asj.12349.

Tong, A. K. W., B. W. Kennedy, and J. E. Moxley. 1979. Heritabilities and genetic correlations for the first three lactations from records subject to culling. J. Dairy Sci. 62:1784-1790. https://doi.org/10 .3168/jds.S0022-0302(79)83497-9.

Trus, D., and J. W. Wilton. 1988. Genetic parameters for maternal traits in beef cattle. Can. J. Anim. Sci. 68:119-128. https://doi .org/10.4141/cjas88-011.

Tsuruta, S., I. Misztal, and T. J. Lawlor. 2004. Genetic correlations among production, body size, udder, and productive life traits over time in Holsteins. J. Dairy Sci. 87:1457-1468. https://doi.org/10 .3168/jds.S0022-0302(04)73297-X.

Tsuruta, S., I. Misztal, and I. Strandén. 2001. Use of the preconditioned conjugate gradient algorithm as a generic solver for mixedmodel equations in animal breeding applications. J. Anim. Sci 79:1166. https://doi.org/10.2527/2001.7951166x.

Turner, A. W., D. Wong, C. N. Dreisbach, and C. L. Miller. 2018. GWAS reveal targets in vessel wall pathways to treat coronary artery disease. Front. Cardiovasc. Med. 5:72. https://doi.org/10 $.3389 /$ fcvm.2018.00072.

Uemoto, Y., T. Osawa, and J. Saburi. 2017. Effect of genotyped cows in the reference population on the genomic evaluation of Holstein cattle. Animal 11:382-393. https://doi.org/10.1017/ S1751731116001762.

van Der Werf, J. H. J., M. E. Goddard, and K. Meyer. 1998. The use of covariance functions and random regressions for genetic evaluation of milk production based on test day records. J. Dairy Sci. 81:3300-3308. https://doi.org/10.3168/jds.S0022-0302(98)75895 $-3$.

VanRaden, P. M. 2008. Efficient methods to compute genomic predictions. J. Dairy Sci. 91:4414-4423. https://doi.org/10.3168/jds .2007-0980.

VanRaden, P. M., C. P. Van Tassell, G. R. Wiggans, T. S. Sonstegard, R. D. Schnabel, J. F. Taylor, and F. S. Schenkel. 2009. Invited review: Reliability of genomic predictions for North American Holstein bulls. J. Dairy Sci. 92:16-24. https://doi.org/10.3168/jds .2008-1514.

VanRaden, P. M., G. R. Wiggans, and C. A. Ernst. 1991. Expansion of projected lactation yield to stabilize genetic variance. J. Dairy Sci. 74:4344-4349. https://doi.org/10.3168/jds.S0022-0302(91)78630 $-\mathrm{X}$

Verardo, L. L., M. S. Lopes, P. Mathur, O. Madsen, F. F. Silva, M. A. M. Groenen, E. F. Knol, P. S. Lopes, and S. E. F. Guimarães, 2017. Gene networks for total number born in pigs across diver- 
gent environments. Mamm. Genome 28:426-435. https://doi.org/ 10.1007/s00335-017-9696-5.

Vitezica, Z. G., I. Aguilar, I. Misztal, and A. Legarra. 2011. Bias in genomic predictions for populations under selection. Genet. Res. (Camb.) 93:357-366. https://doi.org/10.1017/ S001667231100022X.

Voelker, D. E. 1981. Dairy herd improvement associations. J. Dairy Sci. 64:1269-1277. https://doi.org/10.3168/jds.S0022-0302(81)82700 -2 .

Von Bertalanffy, L. 1957. Quantitative laws in metabolism and growth. Q. Rev. Biol. 32:217-231. https://doi.org/10.1086/401873.

Wade, K. M., and R. L. Quaas. 1993. Solutions to a system of equations involving a first-order autoregressive process. J. Dairy Sci. 76:3026-3032. https://doi.org/10.3168/jds.S0022-0302(93)77642 -0 .

Wang, H., I. Misztal, I. Aguilar, A. Legarra, R. L. Fernando, Z. Vitezica, R. Okimoto, T. Wing, R. Hawken, and W. M. Muir. 2014a. Genome-wide association mapping including phenotypes from relatives without genotypes in a single-step (ssGWAS) for 6-week body weight in broiler chickens. Front. Genet. 5:134. https://doi .org/10.3389/fgene.2014.00134.

Wang, W., Z. Feng, S. B. Bull, and Z. Wang. 2014b. A 2-step strategy for detecting pleiotropic effects on multiple longitudinal traits. Front. Genet. 5:357. https://doi.org/10.3389/fgene.2014.00357.

Wegman, E. J., and I. W. Wright. 1983. Splines in statistics. J. Am. Stat. Assoc. 78:351. https://doi.org/10.2307/2288640.

Weller, J. I. 1988. Inclusion of partial lactations in the genetic analysis of yield traits by differential weighting of records. J. Dairy Sci. 71:1873-1879. https://doi.org/10.3168/jds.S0022-0302(88)79757 $-\mathrm{X}$.

White, I. M. S., R. Thompson, and S. Brotherstone. 1999. Genetic and environmental smoothing of lactation curves with cubic splines. J. Dairy Sci. 82:632-638. https://doi.org/10.3168/jds.S0022 -0302(99)75277-X.

Wiggans, G. R., J. B. Cole, S. M. Hubbard, and T. S. Sonstegard. 2017. Genomic selection in dairy cattle: The USDA experience. Annu. Rev. Anim. Biosci. 5:309-327. https://doi.org/10.1146/ annurev-animal-021815-111422.

Wiggans, G. R., T. A. Cooper, P. M. VanRaden, and J. B. Cole. 2011 Technical note: Adjustment of traditional cow evaluations to improve accuracy of genomic predictions. J. Dairy Sci. 94:6188-6193. https://doi.org/10.3168/jds.2011-4481.

Wiggans, G. R., and M. E. Goddard. 1997. A computationally feasible test day model for genetic evaluation of yield traits in the United States. J. Dairy Sci. 80:1795-1800. https://doi.org/10.3168/jds .S0022-0302(97)76113-7.

Wiggans, G. R., and L. D. Van Vleck. 1979. Extending partial lactation milk and fat records with a function of last-sample produc- tion. J. Dairy Sci. 62:316-325. https://doi.org/10.3168/jds.S0022 $-0302(79) 83242-7$

Wilmink, J. B. M. 1987. Adjustment of test-day milk, fat and protein yield for age, season and stage of lactation. Livest. Prod. Sci. 16:335-348. https://doi.org/10.1016/0301-6226(87)90003-0.

Winkelman, A. M., D. L. Johnson, and B. L. Harris. 2015. Application of genomic evaluation to dairy cattle in New Zealand. J. Dairy Sci. 98:659-675. https://doi.org/10.3168/jds.2014-8560.

Wood, P. D. P. 1967. Algebraic model of the lactation curve in cattle. Nature 216:164-165. https://doi.org/10.1038/216164a0.

Xie, L. C. Luo, C. Zhang, R. Zhang, J. Tang, Q. Nie, L. Ma, X. Hu, N. Li, Y. Da, and X. Zhang. 2012. Genome-wide association study identified a narrow chromosome 1 region associated with chicken growth traits. PLoS One 7:e30910. https://doi.org/10.1371/ journal.pone.0030910.

Yang, R. 2006. Mapping quantitative trait loci for longitudinal traits in line crosses. Genetics 173:2339-2356. https://doi.org/10.1534/ genetics.105.054775.

Yang, R., H. Gao, X. Wang, J. Zhang, Z. B. Zeng, and R. Wu. 2007. A semiparametric approach for composite functional mapping of dynamic quantitative traits. Genetics 177:1859-1870. https://doi .org/10.1534/genetics.107.077321.

Yang, R., and S. Xu. 2007. Bayesian shrinkage analysis of quantitative trait loci for dynamic traits. Genetics 176:1169-1185. https://doi .org/10.1534/genetics.106.064279.

Yin, T., B. Bapst, U. U. v. Borstel, H. Simianer, and S. König. 2012. Genetic parameters for Gaussian and categorical traits in organic and low input dairy cattle herds based on random regression methodology. Livest. Sci. 147:159-169. https://doi.org/10.1016/j.livsci 2012.04.017.

Zamani, P., M. R. Moradi, D. Alipour, and F. Ghafouri-Kesbi. 2016. Combination of B-Spline and Legendre functions in random regression models to fit growth curve of Moghani sheep. Small $\mathrm{Ru}-$ min. Res. 145:115-122. https://doi.org/10.1016/j.smallrumres .2016.11.006.

Zavadilová, L., J. Jamrozik, and L. R. Schaeffer. 2005. Genetic parameters for test-day model with random regressions for production traits of Czech Holstein cattle. Czech J. Anim. Sci. 50:142-154.

Zhao, J., Y. Zhao, Z. Song, H. Liu, Y. Liu, and R. Yang. 2018. Genetic analysis of the main growth traits using random regression models in Japanese flounder (Paralichthys olivaceus). Aquacult. Res. 49:1504-1511. https://doi.org/10.1111/are.13605.

Zhao, W., W. Hou, R. C. Littell, and R. Wu. 2005. Structured antedependence models for functional mapping of multiple longitudinal traits. Stat. Appl. Genet. Mol. Biol. 4. https://doi.org/10.2202/ 1544-6115.1136. 